\title{
Sweet Selenium: Synthesis and Properties of Selenium-Containing Sugars and Derivatives
}

\author{
Francesca Mangiavacchi ${ }^{1, *}$, Italo Franco Coelho Dias ${ }^{1,2}$, Irene Di Lorenzo ${ }^{1}$, Pawel Grzes ${ }^{3}$, \\ Martina Palomba ${ }^{1}$, Ornelio Rosati ${ }^{1}$ (D) , Luana Bagnoli ${ }^{1}$ (D), Francesca Marini ${ }^{1}$ (D) Claudio Santi $^{1}$ (D), \\ Eder Joao Lenardao ${ }^{2}$ and Luca Sancineto ${ }^{1, *(\mathbb{D})}$ \\ 1 Group of Catalysis, Synthesis and Organic Green Chemistry, Department of Pharmaceutical Sciences, \\ University of Perugia, Via del Liceo 1, 06100 Perugia (PG), Italy; italo@chemist.com (I.F.C.D.); \\ iry.arg@gmail.com (I.D.L.); martina.palomba@unipg.it (M.P.); ornelio.rosati@unipg.it (O.R.); \\ luana.bagnoli@unipg.it (L.B.); francesca.marini@unipg.it (F.M.); claudio.santi@unipg.it (C.S.) \\ 2 Laboratory of Clean Organic Synthesis, Federal University of Pelotas, Pelotas 96010-900, Brazil; \\ lenardao@ufpel.edu.br \\ 3 Department of Chemistry, University of Białystok, ul. Ciołkowskiego 1K, 15-245 Białystok, Poland; \\ pawel.grzes1993@gmail.com \\ * Correspondence: francesca.mangiavacchi@studenti.unipg.it (F.M.); luca.sancineto@unipg.it (L.S.)
}

Received: 5 August 2020; Accepted: 25 August 2020; Published: 26 August 2020

\begin{abstract}
In the last decades, organoselenium compounds gained interest due to their important biological features. However, the lack of solubility, which characterizes most of them, makes their actual clinical exploitability a hard to reach goal. Selenosugars, with their intrinsic polarity, do not suffer from this issue and as a result, they can be conceived as a useful alternative. The aim of this review is to provide basic knowledge of the synthetic aspects of selenosugars, selenonium salts, selenoglycosides, and selenonucleotides. Their biological properties will be briefly detailed. Of course, it will not be a comprehensive dissertation but an analysis of what the authors think is the cream of the crop of this interesting research topic.
\end{abstract}

Keywords: selenium; sugar; selenoglycosides; water-soluble

\section{Introduction}

Organoselenium compounds are gaining interest in the medicinal chemistry community due to their promising biological activities for a wide range of clinical applications [1-7]. Starting from Ebselen, the first compound showing the ability to function as glutathione peroxidase (GPx) mimetic [8], several Se-bearing molecules were reported as anticancer [9-12], anti-inflammatory [13,14], antidepressant [15,16], and antibacterial [17-19], among others. Worth mentioning, some of us developed the DiSeBAs class of compounds [20], endowed with a potent anti-HIV activity due to their ability to inhibit the key viral protein NCp7 [21,22]. In the antiviral research field, Ebselen was recently discovered as the most potent inhibitor of the main protease belonging to the pandemic coronavirus SARS-Cov-2 [23].

The analysis of the physicochemical properties of investigational molecules is a pivotal aspect for scientists involved in designing a pharmacologically active compound. In particular, a certain degree of aqueous solubility is a feature that a compound needs to possess to become bioavailable when administered orally $[24,25]$. Even if organoselenium compounds do showcase important biological properties, their actual clinical exploitability could be hampered by the low aqueous solubility which precludes them from reaching therapeutically relevant doses in blood. A possible strategy to overcome this barrier is to combine the important pharmacological properties of selenium with the physicochemical properties of sugars, leading to the class of selenosugars and their derivatives, that 
are the object of the present review article. With this in mind, we aim to review the organoselenium compounds endowed with the highest aqueous solubility, at least from a chemical point of view. Most of the selenosugars developed to date will be herein detailed highlighting both the pharmacological and the synthetic aspects, in order to equip the reader with useful knowledge to introduce this useful building block in designed compounds.

\section{Selenopyranes and Selenofuranes}

One of the first attempts to explore the synthesis of selenocarbohydrates is reported in the works of Schiesser's group, collected in a recently published perspective [26]. Their interest was mainly focused on the synthesis of both selenopyranes and selenofuranes as potent water-soluble selenium derivatives able to act as potential antioxidants endowed with good oral bioavailability. Based on his experience on the selenium free-radical chemistry, Schiesser proposed the synthesis of 5-seleno-D-pentopyranose protected sugars 1-7 (Figure 1), using two different approaches [27].

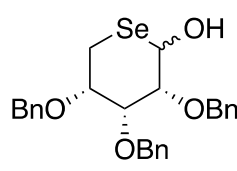

1

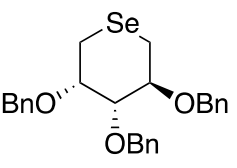

4

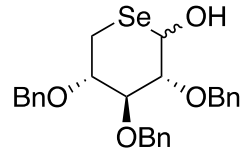

2

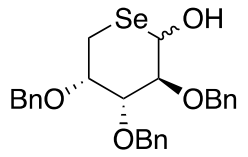

3

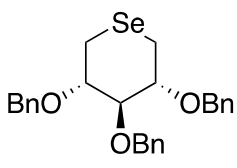

7

Figure 1. Structures of the 5-seleno-pentopyranose.

As depicted in Scheme 1, compound $\mathbf{1}$ was successfully isolated as a mixture of anomers through an intramolecular homolytic substitution mediated by samarium(II) iodide, that triggers the formation of the radical intermediate $\mathbf{1 0}$ from the seleno-aldehyde $\mathbf{9}$, which was in turn obtained from D-ribose [27].

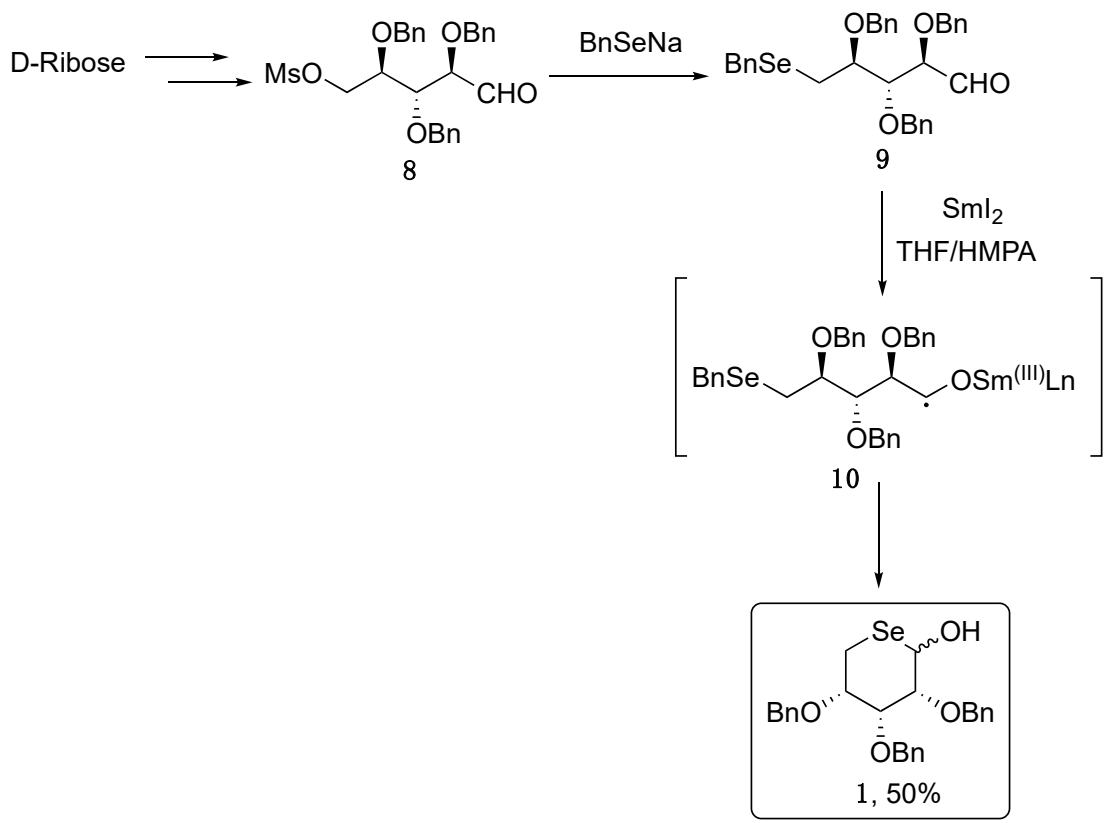

Scheme 1. Synthesis of compound 1. 
The same strategy was applied for the synthesis of $\mathbf{2}$ and $\mathbf{3}$ starting from D-Xylose and D-Arabinose, respectively. On the other hand, compounds 4-7 were prepared by thermolysis of the selenoformate precursors, in which an intramolecular nucleophilic attack of the benzylselanyl group took place, followed by the expulsion of carbon dioxide. Compound 4 was prepared starting from D-arabinose, which was converted into 2,3,4-tri-O-benzyl-5-O-methanesulfonylarabinose $\mathbf{1 1}$ then reduced with $\mathrm{NaBH}_{4}$ and selenofunctionalized through the reaction with benzylselenolate, giving the selenide $\mathbf{1 2}$. Compound $\mathbf{1 2}$ was then activated as selenocarbonate $\mathbf{1 3}$ and finally thermally converted into the target selenosugar 4 . The same synthetic strategy was adopted for the synthesis of 5 but starting from L-arabinose (Scheme 2).

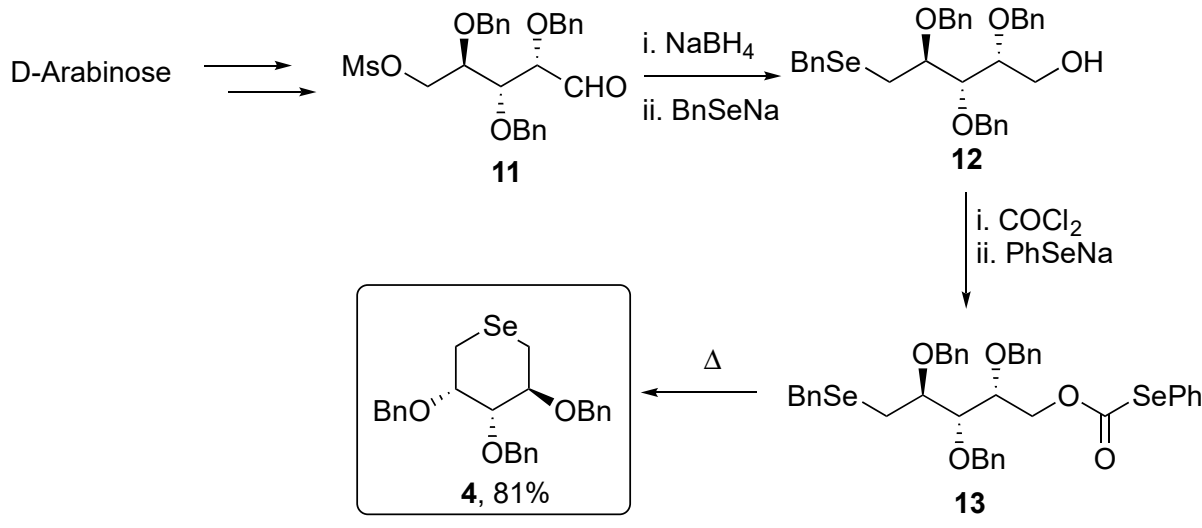

Scheme 2. Synthesis of compound 4.

The synthesis of protected sugars 6 and 7 required a slight modification of the synthetic route to overcome stability issues related to D-ribose and D-xylose analogues of compound 11, hence, the dithioacetals 14 was used instead of the unprotected aldehyde (Scheme 3).

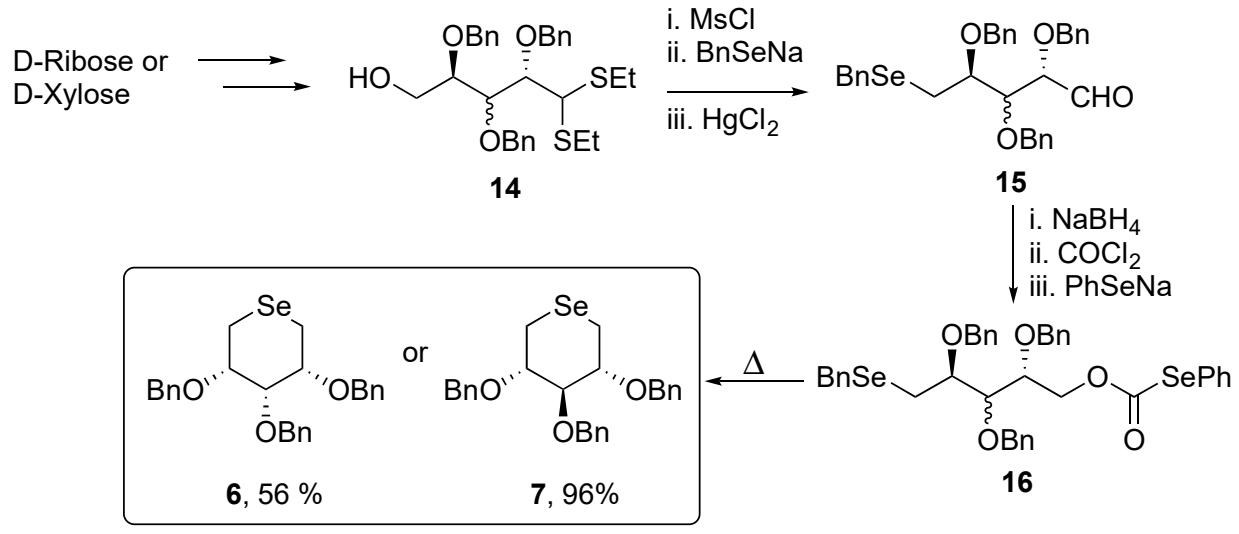

Scheme 3. Synthesis of compounds 6 and 7.

Unfortunately, all the above compounds were not isolated as free sugars due to several issues related to the removal of benzyl groups, which hampered the deprotected derivatives to be obtained. Compounds 17-23 (Figure 2) were instead prepared after the authors developed a different synthetic strategy.

Compounds 17 and 18 were efficiently obtained starting from D-mannose, which was firstly regioselectively protected and then reduced, giving the diol $\mathbf{2 4}$, that was successively activated by bismesylation for the subsequent selenium nucleophilic substitution, affording $\mathbf{1 7}$ after deprotection using TFA (Scheme 4). For the selenosugar 18, a C-5 double inversion strategy was necessary. The diol 24 was quantitatively protected with TBSCl and then subjected to Swern oxidation, yielding $\mathbf{2 6}$ in nearly quantitative yield. The keto moiety was stereoselectively converted into the key alcohol by employing the Luche-type reductive conditions, and then activated as mesylate in compound $\mathbf{2 7 .}$ 
Finally, its treatment with an ethanolic solution of $\mathrm{Na}_{2} \mathrm{Se}$ and the successive acidic deprotection gave the target selenosugar 18 [28].<smiles>OCC1[Se]CC(O)C(O)C1O</smiles>

17<smiles>OC[C@H]1[Se]CC(O)[C@H](O)[C@@H]1O</smiles>

18<smiles>OC[C@H]1[Se]C[C](O)[C@H](O)[C@@H]1O</smiles>

19<smiles>OCC(O)[C@H]1[SeH]C[C@@H](O)[C@H]1O</smiles>

20<smiles>OC[C@H](O)[C@H]1[Se]C[C@@H](O)[C@H]1O</smiles>

21<smiles>OC[C@H](O)[C@H]1[Se]C[C@@H](O)[C@H]1O</smiles>

rac-22<smiles>OC[C@H]1O[C@@H]2C[C@@H]1O[C@H]2O</smiles>

23

Figure 2. Structures of compounds 17-23.

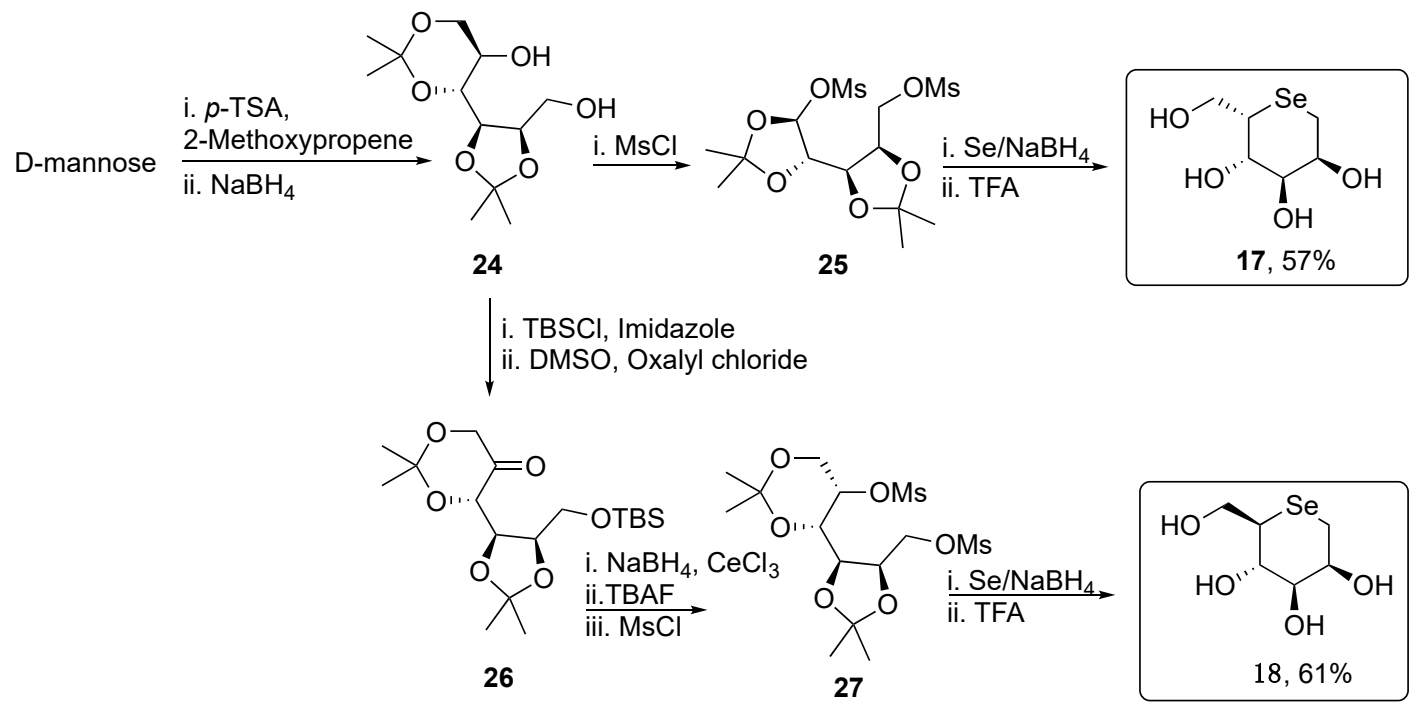

Scheme 4. Synthesis of unprotected selenosugars 17 and 18.

Similarly, seleno-L-gulitol 19 was obtained starting from D-glucose following a similar synthetic pathway, in which selenium is introduced as a nucleophile (Scheme 5) [29].

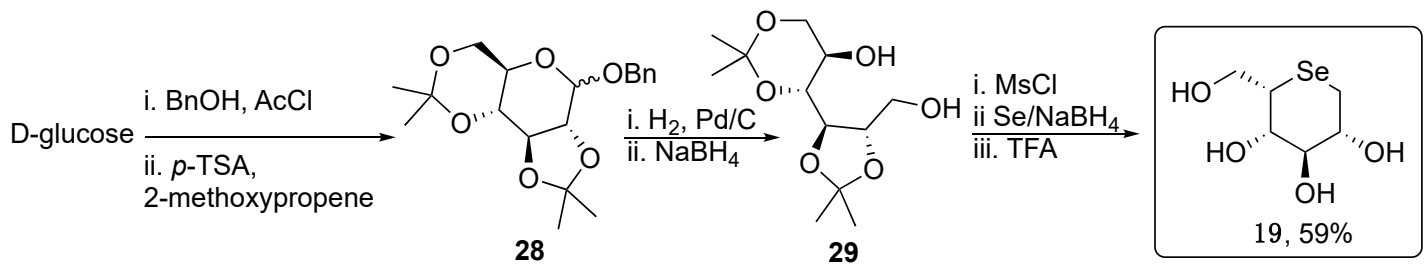

Scheme 5. Synthesis of unprotected selenosugar 19.

A freshly prepared solution of $\mathrm{Na}_{2} \mathrm{Se}$ in ethanol was used also for the preparation of 5-membered selenofurans 20-23, as depicted in Scheme 6. As example, the synthesis of the pyranose 1,4-dideoxy4-seleno-D-talitol 20, began from D-mannose, which was reacted with 2,2-dimethoxypropane in the presence of catalytic $p$-toluenesulfonic acid to give the aldehyde $\mathbf{3 0}$. The reduction of $\mathbf{3 0}$ with sodium borohydride in methanol, followed by reaction with $\mathrm{MsCl}$ gave the corresponding bismethanesulfonate intermediate 31 . Compound $\mathbf{3 1}$ was then converted into the protected selenosugar and finally deprotected by treatment with trifluoroacetic acid in dichloromethane [29]. 

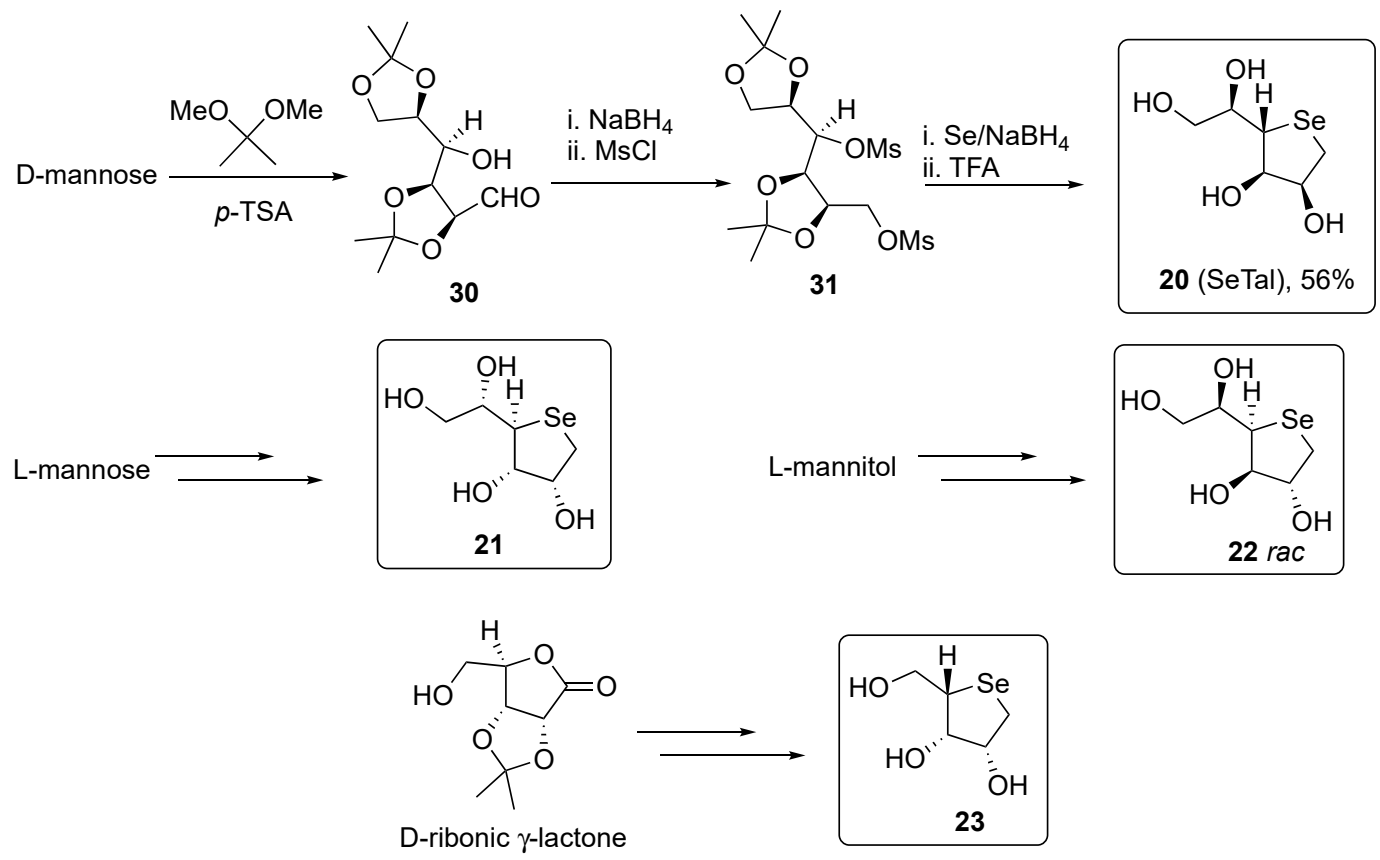

Scheme 6. Synthesis of compounds 20-23.

Similarly to 20, compounds 21-23 were obtained from L-mannose, L-mannitol, and D-ribonic $\gamma$-lactone, respectively, adopting the same synthetic protocol (Scheme 6) [26].

As previously alluded, the great interest in these compounds is related to their ability to act as scavengers against powerful biological oxidants such as hypohalous acids ( $\mathrm{HOX}, \mathrm{X}=\mathrm{Cl}, \mathrm{Br}$ ) produced by mieloperoxidase (MPO) at inflammation sites, and peroxynitrous acid (ONOOH) produced by the activated macrophages. All the above-mentioned oxidants are part of the cellular arsenal defense against pathogens and at low concentrations act as a key signal for the innate immune response [30,31]. Therefore, their production is finely controlled and perfectly balanced. As these finely controlled defense mechanisms are perturbed, the so-called "oxidative stress" status occurs [32], leading to a number of human diseases such as asthma, metabolic disorders, cardiovascular diseases, some neurodegenerative conditions, just to cite some [33].

The second-order rate constant of sugars 17-20 with hypohalous acid has been determined to explore the ability of such compounds to protect sensitive biological targets (such as thiols, sulfides, proteins, nucleic acids, etc.) against oxidative damage. The 1,4-anhydro-4-seleno-D-talitol (SeTal, 20) has revealed itself as a very interesting case study, showing good scavenger activity for several biological relevant oxidants $(\mathrm{HOCl}, \mathrm{HOBr}, \mathrm{HOSCN}, \mathrm{ONOOH})$ in vitro and in human plasma $[29,34]$.

SeTal reacts removing these dangerous chemicals and turns into the corresponding selenoxyde derivative, which is then reduced back to selenide thanks to the abundant presence of cellular thiols, such as glutathione (GSH, Figure 3) [35]. Given its high antioxidant profile, SeTal (20) was further investigated regarding its potential therapeutic application in the context of the wound healing process.

Impaired wound healing is a key marker of type 2 diabetes, where endothelial disfunction is related to high glucose levels that triggers the formation of reactive oxygen species (ROS). In vitro studies have showed that SeTal (20) prevents high-glucose-induced endothelial dysfunction in mouse aorta, suggesting that this selenosugar is capable of repairing endothelial dysfunction brought on by the diabetic condition [36]. In light of this, compound $\mathbf{2 0}$ was tested for its ability to restore the wound healing process in vivo. Investigations carried out on diabetic mice showed a significant increase of wound healing from $40 \%$ to $80 \%$ after 10 days using a $1 \mathrm{mM}$ solution of selenosugar. The wound-healing properties of SeTal were found to be superior to that of other water-soluble selenides [26]. 


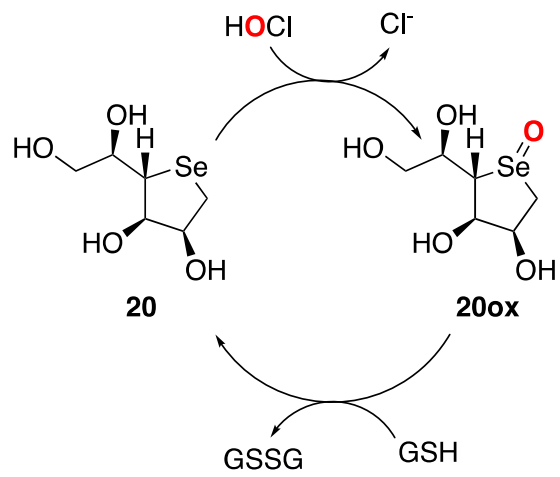

Figure 3. Catalytic cycle of 1,4-anhydro-4-seleno-D-talitol (SeTal) (20).

Selenopyranoses, bioisosters of natural $O$ or $N$-containing sugars, have been also investigated as glycosidase inhibitors. Glycosidases are a group of enzymes that catalyze the hydrolysis of glycosidic linkages degrading oligosaccharides and glycoconjugates [37]. Their broad activity makes them suitable targets for the development of anticancer, anti-type 2 diabetes, and antiviral agents [38].

Recently, Merino-Montiel et al. reported the synthesis of compound 32 and tested its ability to act as a glycosidase inhibitor in analogy with the natural, potent inhibitor isofucofagomine 33. Starting from L-arabinose, the synthetic strategy relies on the formation of the key activated intermediate 34, which reacted with nucleophilic selenium generated in situ by reduction of elemental selenium with $\mathrm{NaBH}_{4}$ (Scheme 7). The authors were also interested in understanding how the oxidation state of selenium affects its biological activity, and therefore the methylated and oxidized derivatives 36 and 38 were also prepared. Compounds 32, 36, and 38 were investigated for their ability to inhibit $\alpha$ - and $\beta$-glucosidase as well as $\alpha$-L-fucosidase. A beneficial effect of the positive charge on the selenium atom reflected by the higher activity of compound $\mathbf{3 6}$ with respect to 32 was observed. Furthermore, selenoxide $\mathbf{3 8}$, although less active with respect to the natural iminosugar 33, showed high selectivity for the $\alpha$-L-fucosidase. Besides, the ability to mimic the antioxidant activity of Gluthathione Peroxidase (GPx) was also tested by evaluating the capacity of the protected compound 35 for scavenging hazardous ROS, such as hydrogen peroxide. When tested at $10 \mathrm{~mol} \%$, compound 35 displayed a $\mathrm{T}_{50}$ of $32 \mathrm{~min}$ [39].

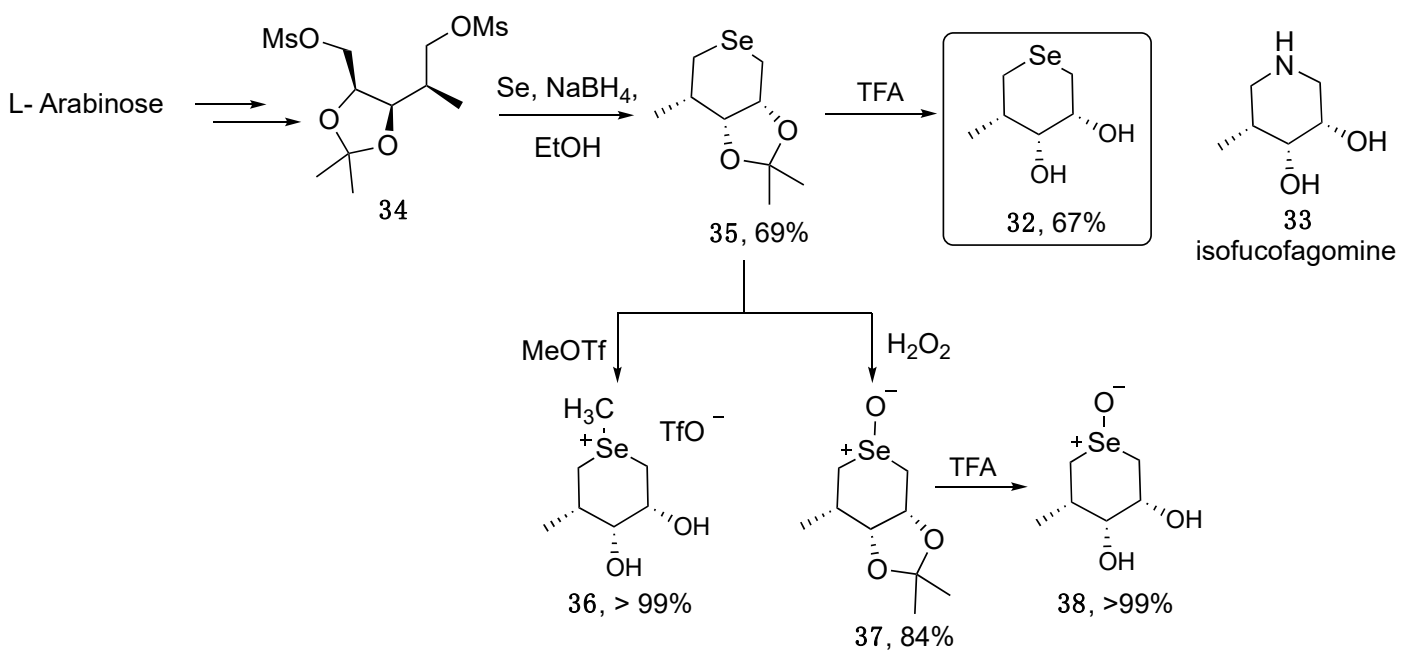

Scheme 7. Synthesis of Se-analogues of isofucofagomine.

\section{Selenonium Salts}

Selenonium salt derivatives of selenosugars are surely worth mentioning. They were initially prepared as a result of the pioneering work of Pinto and colleagues, who first developed the synthetic protocol for their preparation. 
The interest of Pinto's group was related to the development of selenium isosters of the active sulfonium salt derivatives, largely distributed in the plants of Salacia species. In particular, the root, leaf, and stem extracts from Salacia reticulata have been widely used in the Ayurvedic and traditional medicine for the treatment of diabetes and as a food supplement due to its ability to prevent obesity, especially in Japan and the USA [40,41]. Diabetes is a complex metabolic disease often associated with cardiovascular complications and other pathologies. The WHO (World Health Organization) has esteemed 60 million people affected by diabetes in the European area, with a large increase in different age groups. Type 2 diabetes is considered one of the main causes of morbidity and mortality worldwide which, unfortunately, is predicted to increase its spread, and more importantly, it is the fourth cause of death in most of the developed countries [42]. Therefore, the prevention, as well as the development of good therapeutic strategies able to control the high levels of glucose and all of the diabetes complications, are highly desirable.

The active compounds from Salacia species are displayed in Figure 4. Salaprinol (39), salacinol (41), ponkoranol (43), kotalanol (45), and the corresponding de-O-sulfonated derivatives 40, 42, 44, and 46 (Figure 3) have been correlated with the ability to modulate both lipidic and carbohydrate metabolism, in the latter case because of their glycosidases inhibitory property [41,43].

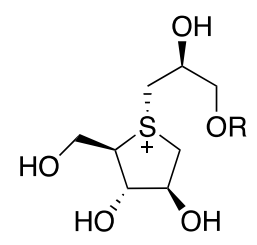

$39 \mathrm{R}=\mathrm{SO}_{3}^{-}$
$40 \mathrm{R}=\mathrm{H}$<smiles>OCC1C(O)C(O)C=S1C[C@@H](O)CO</smiles>

$41 \mathrm{R}=\mathrm{SO}_{3}^{-}$
$42 \mathrm{R}=\mathrm{H}$<smiles>OCC(O)C(O)C(O)C(O)C[SH]1CC(O)C(O)C1O</smiles>

$43 \mathrm{R}=\mathrm{SO}_{3}^{-}$

$44 \mathrm{R}=\mathrm{H}$<smiles>OCC(O)C(O)C(O)C(O)C(O)CC1CC(O)C(O)C1CO</smiles>

$45 \mathrm{R}=\mathrm{SO}_{3}^{-}$

$46 \mathrm{R}=\mathrm{H}$

Figure 4. Structure of active compounds in Salacia species.

Over a decade, Pinto and co-workers largely contributed to the structural elucidation of the cited active components of Salacia species [44]. In addition, they widely explored the structural modifications of such compounds and the effect on the inhibitory activity of maltase-glucoamylase (MGAM) and sucrase-isomaltase (SI) [45-47]. Both MGAM and SI are intestinal $\alpha$-glucosidase enzymes responsible for the hydrolysis of polysaccharides resulting in the glucose release and absorption, therefore considered suitable targets for the development of anti-diabetes drugs [48].

The introduction of selenium as a replacer of sulfur in the aldose skeleton of salacinol (compound 41, Figure 4) resulted in blintol (47, Figure 5), which showed a really good inhibitory activity against human intestinal glucosidases. The activity was explained by a perfect superimposition of 1,4-anhydro4-seleno-D-arabinitol ion with the oxacarbonium intermediate from the transition state of the glycoside bond breakage [49]. Starting from blintol, Pinto's group has synthesized and investigated a great variety of derivatives that will be hereafter briefly summarized in two main groups:

- Modifications of the heterocyclic ring, and

- Modification on the polyhydroxylated chain.
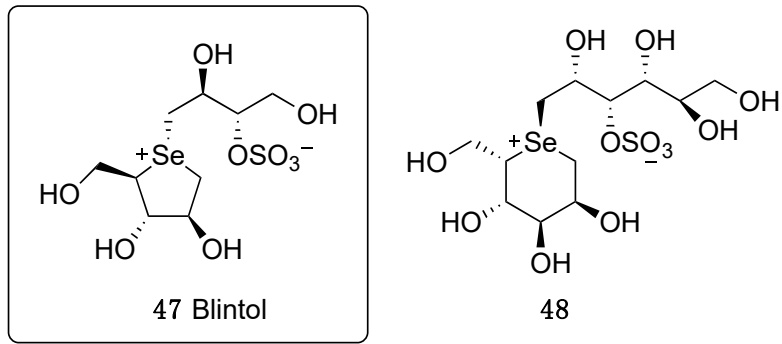<smiles>O=S(=O)([O-])O[C@@H]1C[C@H](O)[C@@H](O)[C@H]1[C@H](O)CO</smiles>

Figure 5. Structures of selenosugars 47-49. 


\subsection{Modification of the Heterocyclic Ring}

The replacement of sulfur by the heavier chalcogen selenium positively affected the inhibition activity against glycosidase enzymes, showing also the ability to be selective on some of them. Indeed, compound 47 was capable of inhibiting three glycosidase enzymes, namely glucoamylase G2, porcine pancreatic R-amylase, and barley R-amylase, beside the human MGAM [50,51]. The synthesis and investigation of the six-member analogue, 1,5-anhydro-1-seleno-L-gulitol derivative 48 and a different heterocycle configuration, 1,4-anhydro-1-seleno-D-talitol 49, was also reported (Figure 5).

Worth mentioning, the ring-expansion negatively affected the inhibitory activity. As a result, compound 48 is a worse glycosidase inhibitor than 47 , highlighting that the five-member ring is a key structural element for the activity. Furthermore, it has been demonstrated that the configuration of the D-arabinitol ring is another key feature, determinant for the activity $[52,53]$.

\subsection{Modification on the Polyhydroxylated Chain}

Considering the good activity of the C-7 extend chain derivative kotalanol (compound 45, Figure 4) attention has been dedicated to the synthesis of different C-5', C-6', C-7' polyhydroxylated chain derivatives, in which also the stereochemistry of the substituents and the sulfonate group have been modified. In Figure 6 some selected examples are reported.

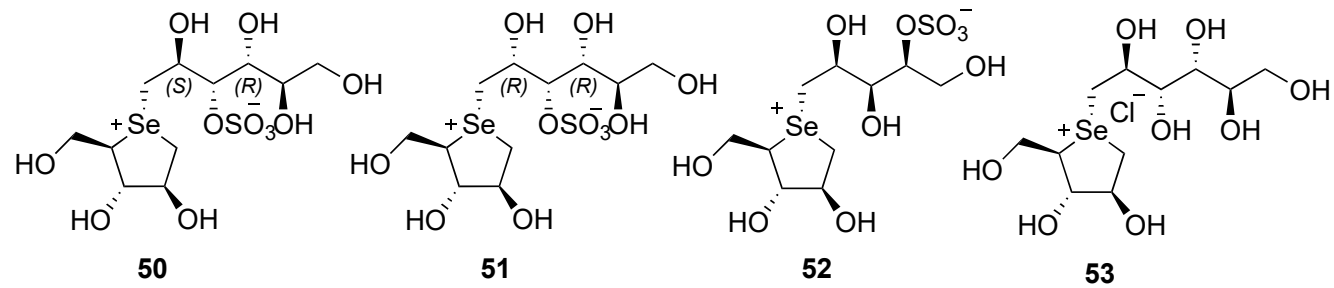

Figure 6. Structures of selenosugars 50-53.

As a general trend, it can be concluded that the elongated chain does not significantly increase the interaction with the active site of the enzyme. The stereochemistry of C-2' and C- $4^{\prime}$ is pivotal for the activity, indeed only the $(2 S, 4 R)$-isomer $\mathbf{5 0}$ is capable of inhibiting the enzyme. The shifting of the sulfonate group from $\mathrm{C}-3^{\prime}$ to $\mathrm{C}-4^{\prime}$ resulted in a less potent compound, while the de-O-sulfonated derivative 53, showed an increased inhibition activity against C-terminal sucrase isomaltase $[49,54,55]$.

Envisioning the need for a large amount of the potential drug candidate in a prospective clinical application, Pinto and co-workers developed an optimized, cost-effective, synthetic protocol able to yield a gram-scale synthesis of blintol (47). From a retrosynthetic perspective, compound 47 can be achieved by linking the two key syntones, namely 2,3,5-tri-O-p-methoxybenzyl-1,4-anhydro- 4-seleno$D$-arabinitol (54) and 2,4-O-benzylidene- $L$-erythritol-1,3-cyclic sulfate (55), the latter can be in turn prepared in five steps starting from D-glucose instead of the more expensive L-glucose (Scheme 8) [56].

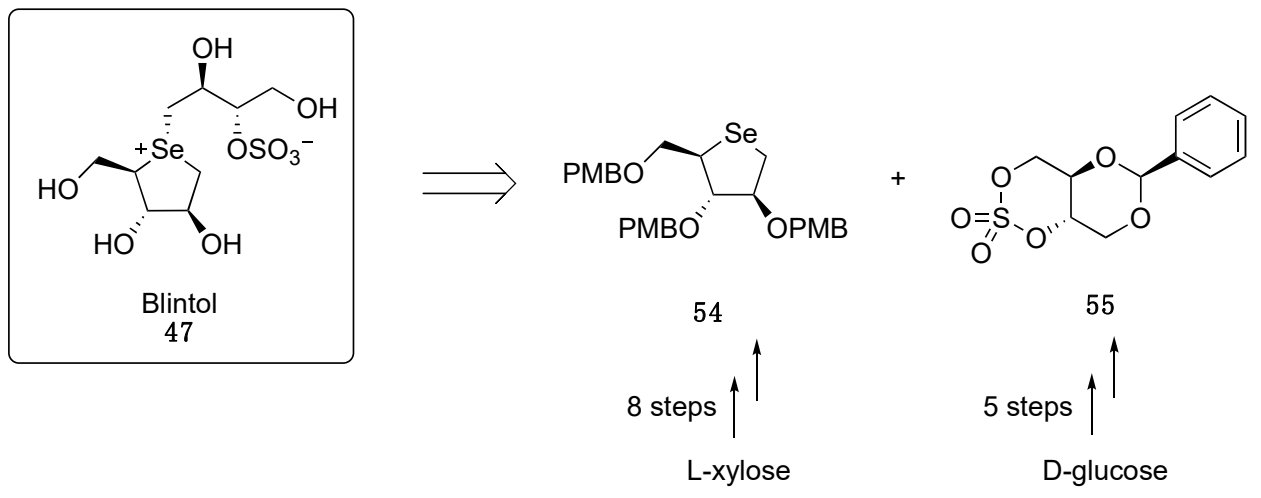

Scheme 8. Retrosynthetic analysis of blintol (47). 
Focusing on the synthesis of intermediate $\mathbf{5 4}$, that is displayed in Scheme 9, there are several points of interest, such as the proper choice of the protecting groups, for example, $p$-methoxybenzyl instead of benzyl ether, which can be easily removed under mild acid conditions; moreover, the use of boric acid in the first step allows to push the equilibrium toward the formation of the furanoside structure, giving access to the protected derivative 56 in a one pot, two steps procedure. A careful investigation was also made to select $n$-pentenyl as the selective protecting group of the anomeric-hydroxyl group in compound 57, which was then easily converted to compound 59, using N-bromosuccinimide (NBS). Finally, the treatment with $\mathrm{NaBH}_{4}$, followed by the reaction with $\mathrm{MsCl}$ gave the activated intermediate $\mathbf{6 0}$, that reacted with nucleophilic selenium generated in situ, affording the desired key intermediate $\mathbf{5 4}$ in a $20 \%$ overall yield [56].

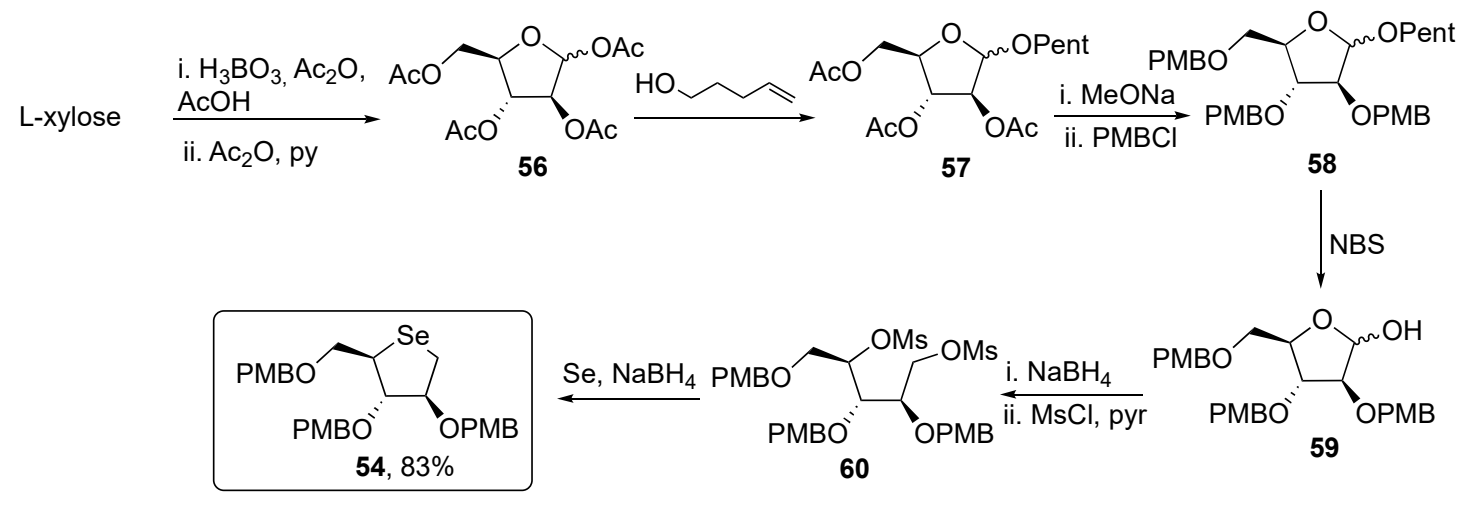

Scheme 9. Synthesis of 54 .

\section{Selenoglycosides}

Selenoglycosides are a class of selenosugars that appeared in the literature in the early 1950s [57], in which the bridging oxygen of the glycosidic bond is replaced by selenium [58]. While their main biological property is the inhibition of glycosidase enzymes, which are unable to break the Se-glycosidic bond, they find synthetic applications in glycosylation procedures for oligosaccharides synthesis [59-62]. Selenoglycosides are used in crystallography thanks to the anomalous dispersion of selenium in response to X-ray irradiation; in this context, the methylselenoglycoside of $N$-acetylglucosamine was employed as a ligand mimetic for the structural determination of carbohydrate-binding protein F17-G adhesin [63]. More recently, the human galectin-9 $N$-terminal carbohydrate recognition domain was crystallized with the aid of selenosugars [64]. In the same context, dodecyl- $\beta$-selenomaltoside has been successfully utilized as a detergent for stabilizing membrane proteins in water [65].

As reported in the general Scheme 10, selenoglycosides $\mathbf{6 1}$ can be prepared by installing the selenium at the anomeric carbon through a classic Koenigs-Knorr type procedure, where the chalcogen belongs to the aglycone that reacts with a protected sugar containing a leaving group $(62$, path $A)$. Usually, the nucleophilic selenolate is used as such, as pioneeringly reported by Bonner and Robinson in the reaction of benzenselenol with peracetyl- $\alpha$-D-glucopyranosyl bromide [57], and more recently by $\mathrm{Di}$ Bussolo and co-workers [66]. Alternatively, it is prepared in situ by the reduction of the corresponding diselenides, far more stable and easy-to-handle $[67,68]$. Examples of this kind of chemistry were reported by Misra, who has developed efficient, indium iodide and zinc-promoted Se-Se bond cleavage procedures $[69,70]$. These reactions proceed with inversion of the configuration at the anomeric carbon and, sometimes, it is not compatible with the protecting groups already present in the sugar.

Alternatively, selenoglycosides can be obtained following path $B$, where the leaving group-containingprotected sugar reacts with potassium selenobenzoate through, supposedly, a $S_{N} 2$ mechanism, affording compound 63 that, after the treatment with $\mathrm{MeONa}$, gives the glycosilselenol 64, which is a good precursor to prepare 61 and other derivatives [71]. The potassium analogue of 64 , compound 66 , can be prepared from the potassium hydroxide-promoted decomposition of the selenopseudoureido derivative 
65, that was in turn prepared through the reaction between selenoureas and 62 (path C). Interestingly, the potassium salt 66 was further evolved into the diselenides 67 [72], valuable compounds per se, but also precursors of nucleophilic (Scheme 10), electrophilic [73], or radical selenium- centered reagents [74]. Sugar diselenides were awfully prepared by Braga and Ludtke using $\mathrm{Li}_{2} \mathrm{Se}_{2}$ as selenylating agent $[75,76]$.

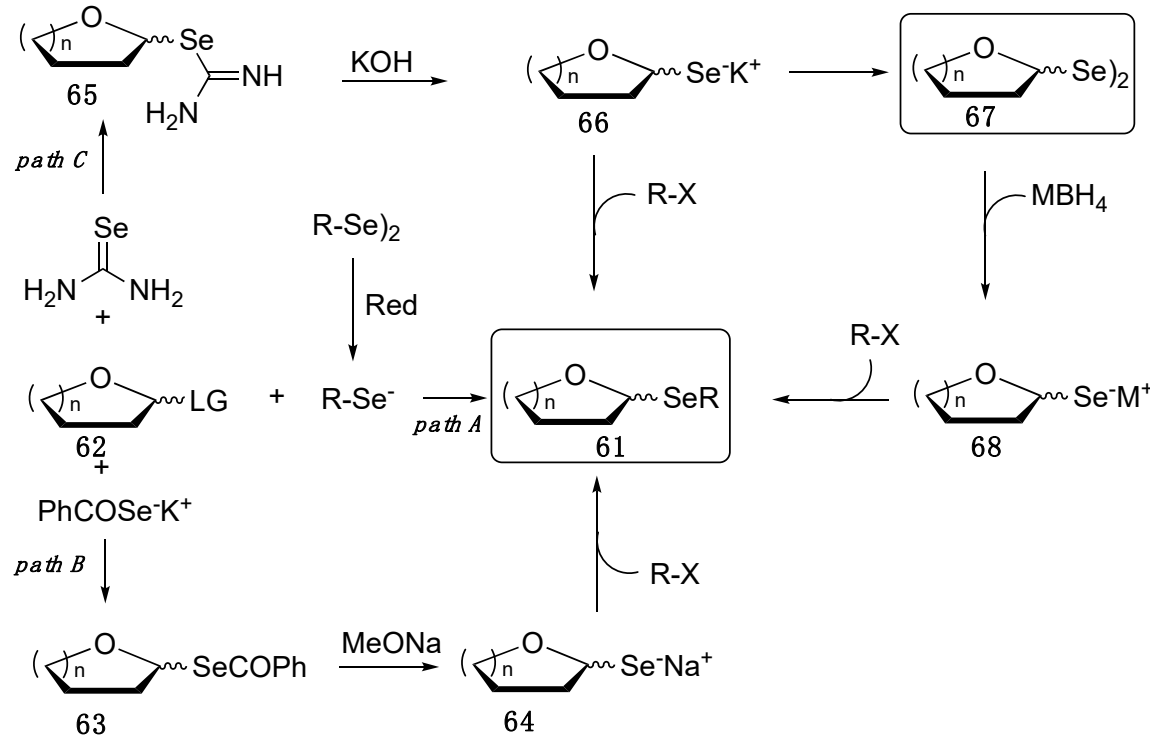

Scheme 10. Synthetic approaches for the synthesis of selenoglycosides.

A recent evolution of the path $C$ methodology was reported by Kumar et al., who prepared selenonucleosides starting from commercially available, activated sugars (69, Scheme 11$)$ and selenourea. The resulting isoselenuronium salts $\mathbf{7 0}$ were isolated and then functionalized with various alkyl, aryl, and acyl moieties or monosaccharides [77]. The authors prepared more than 30 compounds, all deprotected under basic conditions (compounds 72).

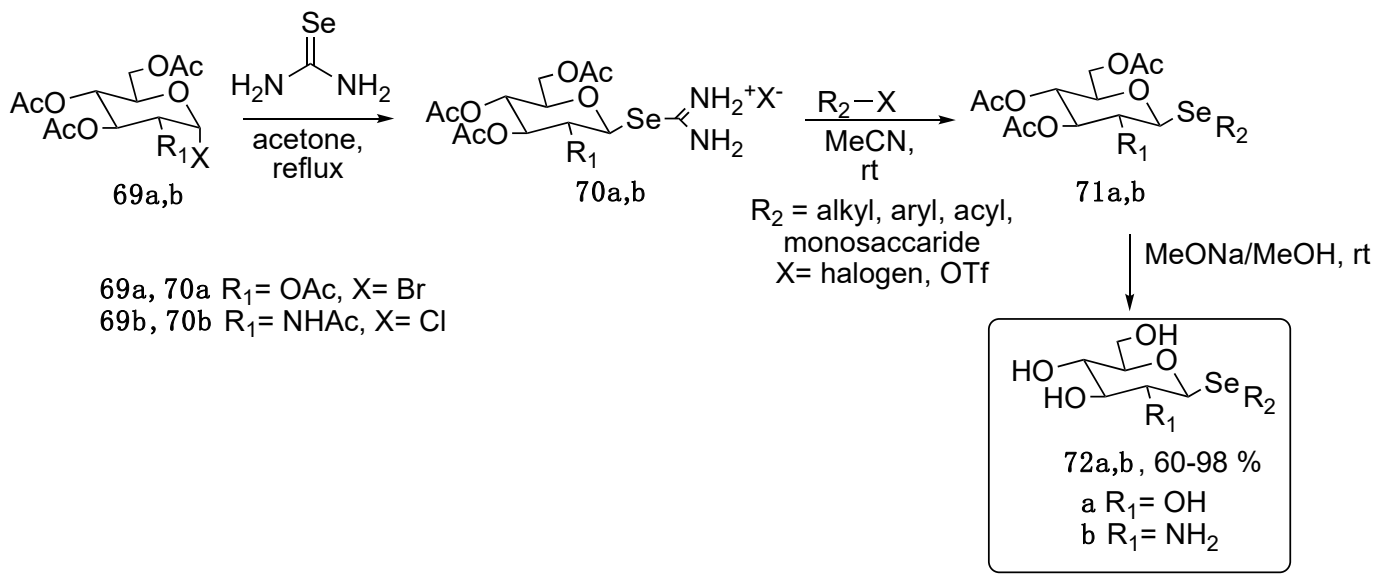

Scheme 11. Synthesis of compound 72.

More recent approaches to prepare these selenocompounds are summarized in Scheme 12. Kiso and co-workers reported a transacetalization reaction between benzyloxymethyl alkyl selenide (73) and the glicosylimidate $\mathbf{7 4}$, leading to the selenoglycosides 75 in high yields. The selenoacetals 73 were obtained by nucleophilic displacement of $\mathbf{7 6}$ with freshly prepared selenolates [78].

Very recently, Townsend and Guan reported the $S_{N} 2$ reaction between peracetylated $\alpha$-glucosyl (69a) and $\alpha$-galactosyl bromides and the selenolate formed in situ through the $\mathrm{NaBH}_{4}$ promoted reduction of arylselenocianates 77 . The reaction afforded stereoselectively the $\beta$-anomer as a result of 
the bimolecular nucleophilic displacement. Worth mentioning, the stated selenocyanates were smartly obtained by arylation of potassium selenocyanate using as electrophilic partner variously functionalized diaryliodonium salts 78 [79].

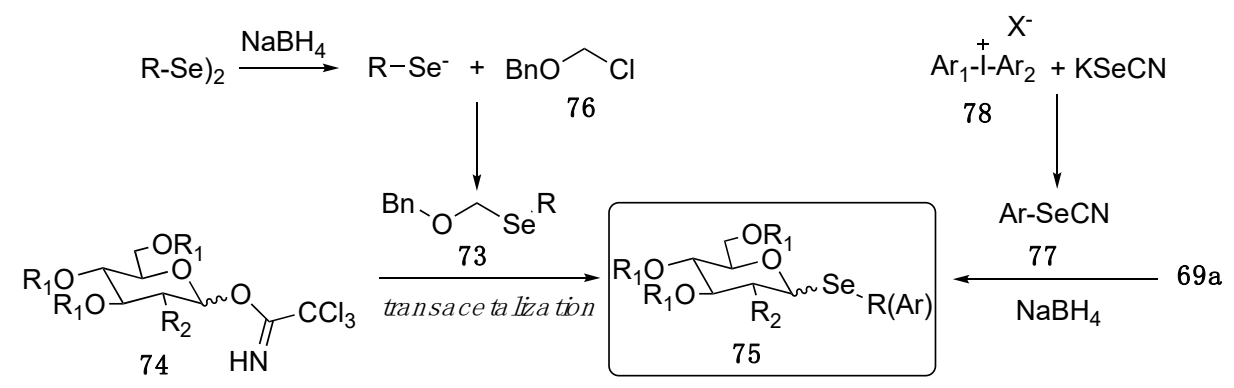

Scheme 12. Approaches to selenoglycosides.

Other exotic Se-centered nucleophiles used in the preparation of selenoglycosides are the selenocarboxylate anions 79. They can be prepared by reacting carboxylic acids with Woollins' reagent [80] or by the nucleophilic activation of $p$-methylselenobenzoic anhydride 80 [64]. Examples of their reactivities in the synthesis of selenoglycosides are reported in Scheme 13. Compound 79 adds to the benzyl protected glucal 81, yielding cleanly and stereoselectively the $\alpha$-adduct 82 . The nucleophilic displacement of the $\alpha$-bromo- peracetyl-D-Glucose gave the protected $\beta$-selenosugar 83 [80]. The removal of the $p$-methylbenzoyl group is feasible and gives the selenolate anion $\mathbf{8 4}$, that acts as synthetic handle to further modify the selenosugars with alkyl and aryl groups, or to prepare selenodisaccarides or, finally, aminoacyl decorated selenosugars [81]. Selenolactose derivatives, obtained through the above-mentioned methods, were used to solve the crystal structure of the human galectin- $9 \mathrm{~N}$-terminal carbohydrate recognition domain. Interestingly the X-ray structure of the selenosugar containing protein was almost the same of the lactose-containing one highlighting that the introduction of the heavier chalcogen did not affect the relative positions of either the protein or the ligands but made the analysis easier [64].

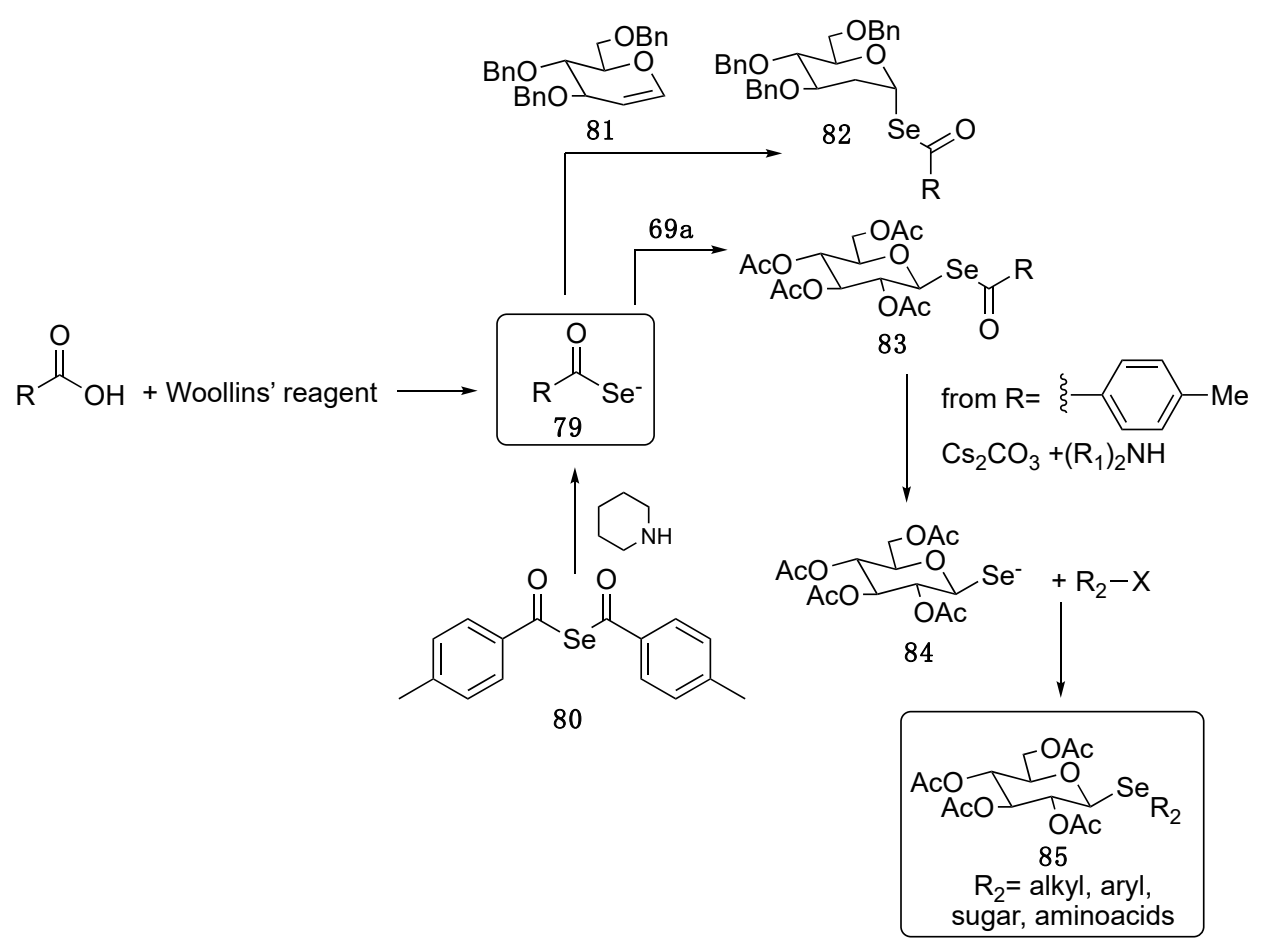

Scheme 13. Selenocarboxylates in the synthesis of selenosugars. 
Using the piperidine-promoted activation of compound 80, Davies and colleagues prepared the selenoester $\mathbf{8 6}$, that was converted into the sugar diselenides $\mathbf{8 7}$ for the synthesis of glycoconjugated molecules bearing the unusual Se-S linkage (Scheme 14). Compound 89, derived from the reaction between $\mathbf{8 7}$ and reduced glutathione $\mathbf{8 8}$, is known as "Hepatic Se metabolite A", which was prepared synthetically because it was just observed, but never isolated from living systems. More complex peptides were also decorated with selenosugars exploiting the same approach $[82,83]$.

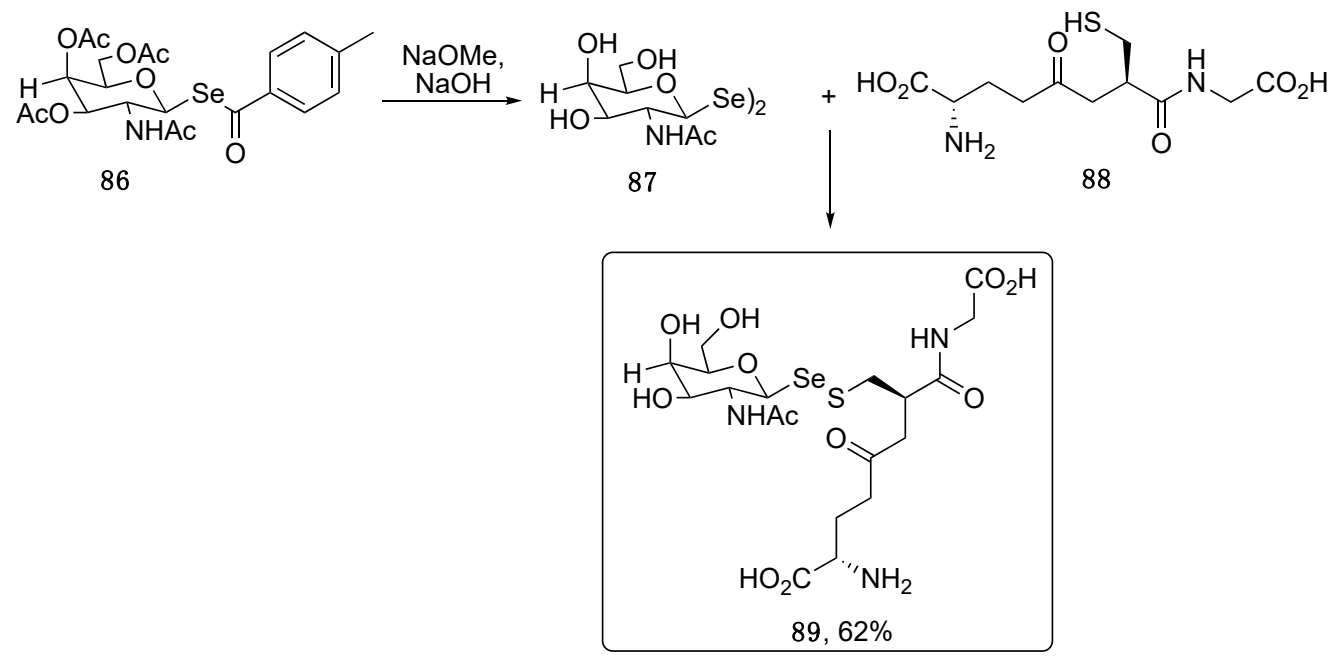

Scheme 14. Synthesis of Hepatic Se metabolite A (89).

Compound $83\left(\mathrm{R}=p-\mathrm{MeC}_{6} \mathrm{H}_{4}\right.$, Scheme 13) was reported as inhibiting melanin synthesis in the context of a wider study aimed to identifying selenocarbohydrates endowed with the ability to modulate the melanin production in melan-a cells through the inhibition of tyrosinase, an enzyme which regulates the melanogenesis. The discovery of tyrosinase inhibitors is important for developing whitening products in both cosmetics and medicine [84].

Selenoglycosides found application in oligosaccharide synthesis. As shown in Scheme 15, Yamago proposed a sort of armed and disarmed glycosylation strategy based on the ability of alkylarylselenides to react with molecular bromine affording the corresponding aryldiselenides and the sugar bearing a bromo group in the $\beta$-anomeric position. The installation of the bromo group served for the reaction with a second selenosugar, that acts as glycosyl acceptor thus forming the disaccharide 93 . Once formed, 93 undergoes activation with the bromo group and then reaction with further selenosugars in order to obtain polysaccharides [85]. This approach was later extended to the combinatorial synthesis of a library of oligosaccharides [86].

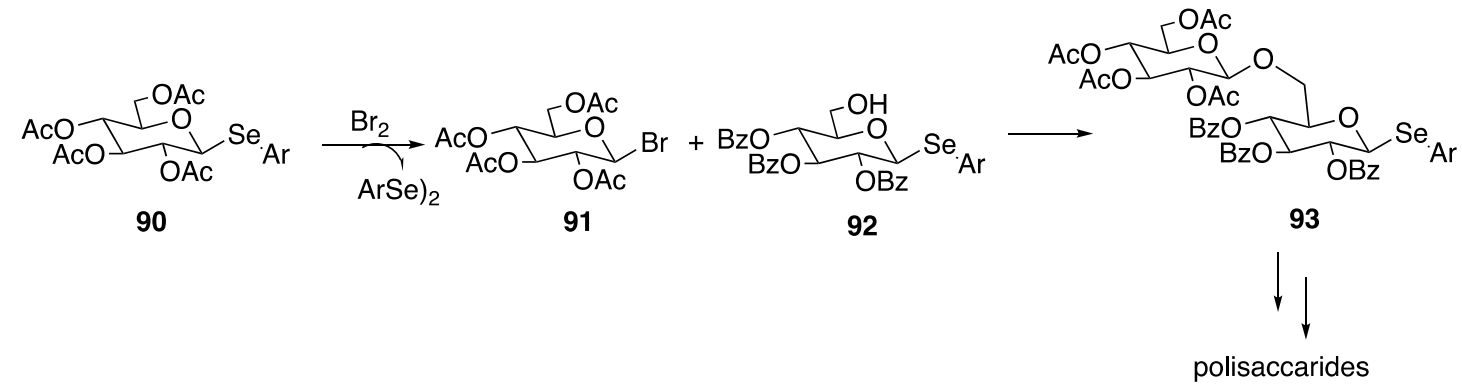

Scheme 15. Synthesis of polysaccharides.

Starting from diselenoglycosides, Braga and Ludtke reported the functionalization of selenolates formed in situ with protected aziridines, affording more complex selenocarbohydrates, named neoglycoconjugates [87]. As depicted in Scheme 16, the furanose derived diselenide 95, prepared through the reaction of $\mathrm{Li}_{2} \mathrm{Se}_{2}$ 
and tosyl furanose 94, was reduced to the corresponding selenol 96, which was not isolated but rapidly reacted with variously functionalized, protected aziridines, giving the target compound 97.
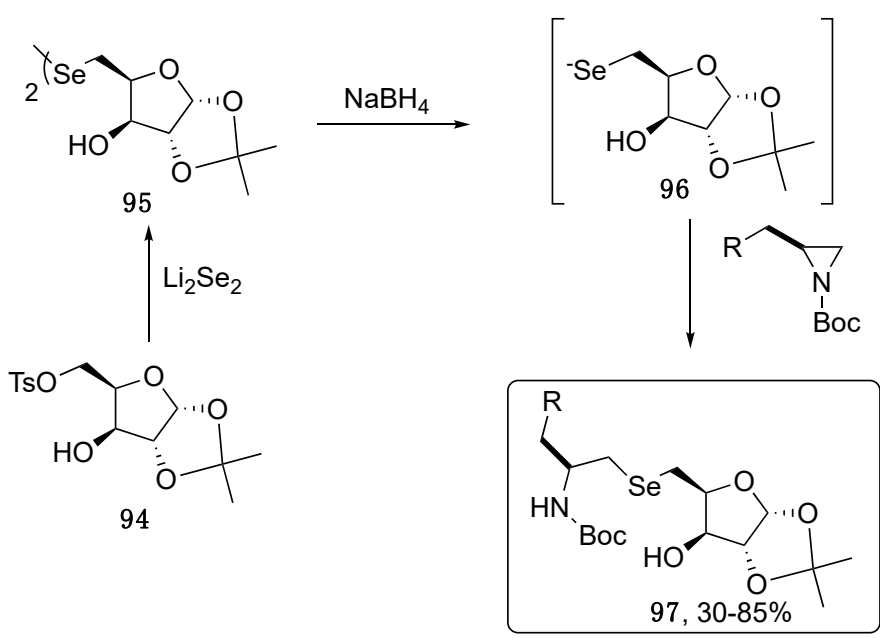

Scheme 16. Synthesis of neoglycoconjugates.

Pseudodisaccharides, where selenium links the two monosaccharides in a position different from the anomeric one, were also obtained $[88,89]$ and the synthetic methods for their preparation were recently collected in a review article in which also their biological properties are discussed. Briefly, selenopseudo disaccharides were studied as lectin binders, that may have a number of potential therapeutic applications such as antibacterial (inhibitors of bacterial lectins), anti-inflammatory (selectins inhibitors), or anticancer (galectins inhibitors) agents [90].

\section{Phosphoroselenoate Oligonucleotides}

Several papers and procedures in the literature report the synthesis and the biological properties of phosphoroselenoates, nevertheless, to the best of our knowledge, no review articles have covered this specific topic. The first report focused on the synthesis of phosphoroselenoate oligonucleotides (Figure 7) can be traced back to 1984, with the paper of Stec and colleagues [91]. Five years later, Mori et al. studied their biological properties as anti-HIV agents [92]. The synthetic methodology mainly relied in the late stage functionalization of phosphite intermediates with $\mathrm{KSeCN}$, giving in general poor yields, even if in the context of an automated procedure [91].

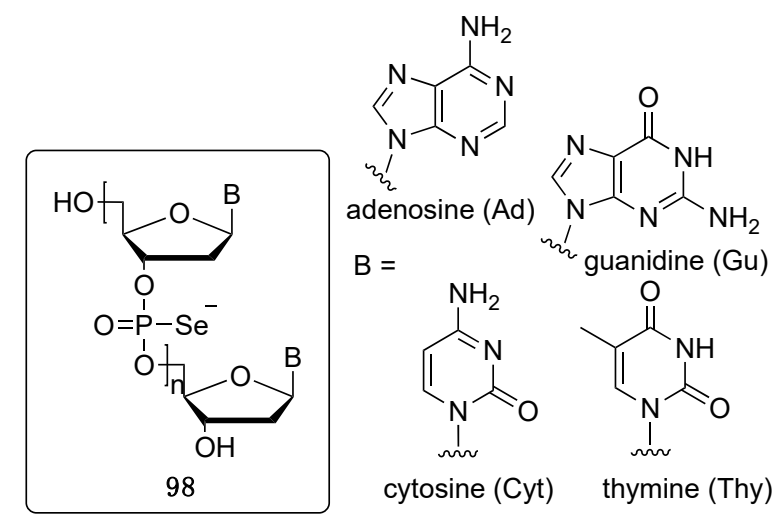

Figure 7. Structures of the phosphoroselenoates synthesized by Stec and studied by Mori.

More recently, Conlon and co-workers proposed the synthesis of phosphoroselenolate oligomers using a multi-step protocol with better yields [93]. As shown in Scheme 17, the first step is the substitution of the tosyl group in the nucleoside 99 at the $\mathrm{C}-5$ position by using an excess of potassium selenocyanate 
under microwave irradiation, in order to obtain the $5^{\prime}$-selenocyanate nucleoside $\mathbf{1 0 0}$ in $75 \%$ yield. The key step of the synthesis is the Michaelis-Arbuzov reaction of the methyl-protected nucleoside $3^{\prime}-H$-phosphonate 101 with compound 100, that afforded the phosphoroselenolate-bridged dimer 102 with high efficiency. The presence of 2,6-lutidine served to improve the solubility of $\mathbf{1 0 0}$ in $\mathrm{CH}_{3} \mathrm{CN}$, and all the dimers were obtained as diasteroisomers. Finally, the phosphitylation of the dimers allowed the preparation of the corresponding phosphoramidites 103, which were then used as starting materials for the successive solid-state synthesis of oligomers, the actual target of these studies $[93,94]$. These selenium containing oligomers were used to observe conformational changes within nucleic acids during folding, recognition, and processing by applying the selenium single wavelength anomalous diffraction.

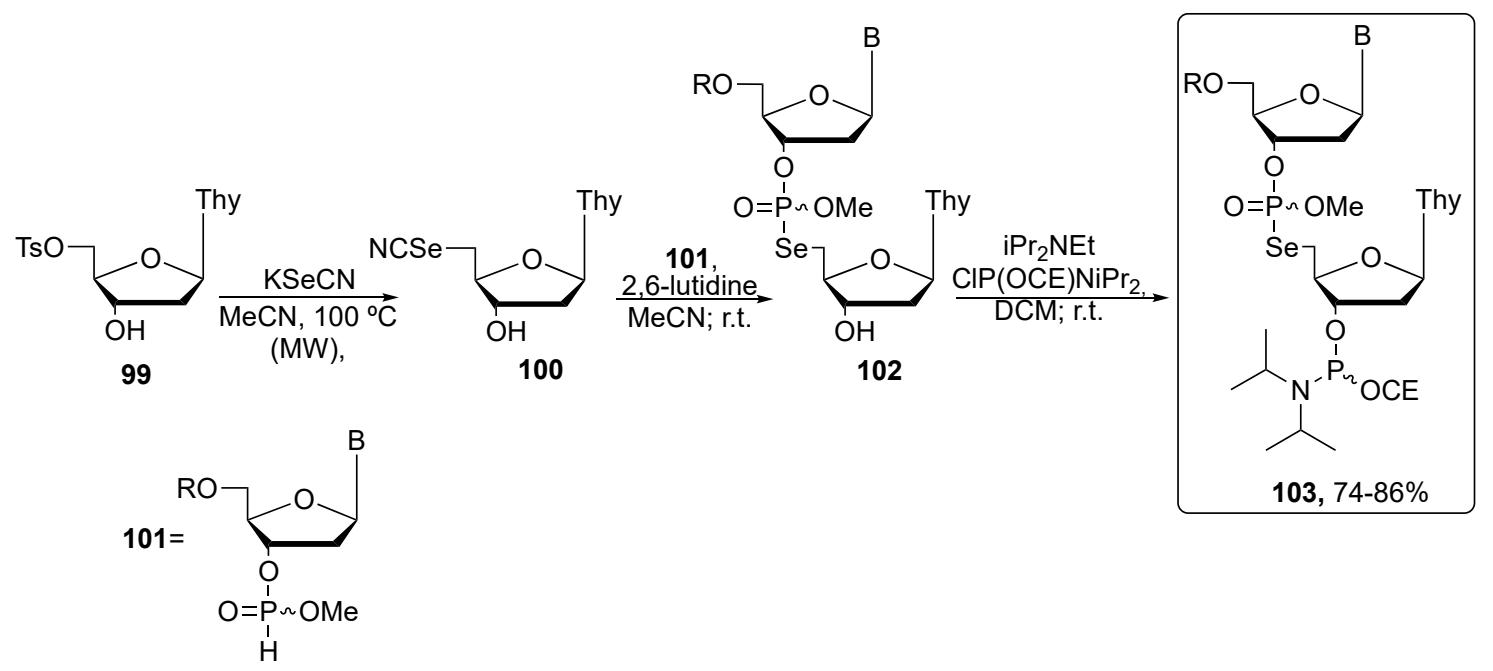

Scheme 17. Synthetic pathway to obtain the phosphoroselenolates through Michaelis-Arbuzov reaction. $\mathrm{R}$ is 4,4'-dimethoxytrityl (DMTr) or 4-methoxytrityl (MMTr); CE: 2-cyanoethyl, and B is one of the DNA bases Cyt, Thy, Gu, Ad.

Alternatively, the phosphoroselenoate fragment can be obtained using $H$-phosphonoselenoate monoester 104 as starting material, as described by Bartoszewic et al. (Scheme 18). After an iodinemediated oxidative pathway, 104 was converted to the intermediate iodoselenyl 105, with a P(III). Under basic conditions, the phosphorus oxidation takes place with the concomitant elimination of iodide, forming the compound 106. The target compound 107 was finally obtained by the treatment of 106 with water $\left(\mathrm{R}_{2}=\mathrm{H}\right)$ or alcohols. The general concept was then applied to the synthesis of dinucleosides. In particular, compound $\mathbf{1 1 0}$ was prepared as a 1:1 diasteromeric mixture, as determined by ${ }^{31} \mathrm{P}$ NMR, in $77 \%$ yield [95].

In 2009, Kowalska and co-workers reported the synthesis of asymmetric phosphoroselenolates, useful as synthetic RNA Cap analogue, and a valuable tool for studying mRNA translation and turnover. As reported in Scheme 19, the treatment of tris(trimethylsilyl)phosphite with elemental selenium in pyridine led to the unstable tris(trimethylsilyl)phosphoroselenoate $\mathbf{1 1 1}$ that, in the presence of the nucleoside $\mathbf{1 1 2}$ and an excess of $\mathrm{ZnCl}_{2}$ as Lewis acid, gives the more stable and easy-to-handle intermediate 113. This latter was then converted into the target compound 115, after its reaction with the imidazole-containing nucleotide 114.

Compound 115 was obtained as a mixture of diasteroisomers, both submitted to biological evaluation for the binding affinities with the eukaryotic initiation factor $4 \mathrm{E}$ (elF4E), a protein responsible for rRNA Cap recognition during the initiation of translation. The presence of selenium generally stabilized the interaction with elF4E, and, as a result, compound $\mathbf{1 1 5}$ binds with higher affinity than the $O$-containing Cap analogues, and similarly to sulfur-containing ones. The mRNA sequences having incorporated compounds $\mathbf{1 1 5}$ at their $5^{\prime}$ ends were efficiently translated, proving that the presence of phosphoroselenoates does not disturb the mRNA's functionality [96]. These derivatives can be 
exploited to RNA-based gene therapy where mRNAs encoding viral- or tumor-associated antigens are transfected in the host dendritic cells triggering an autoimmunization process.
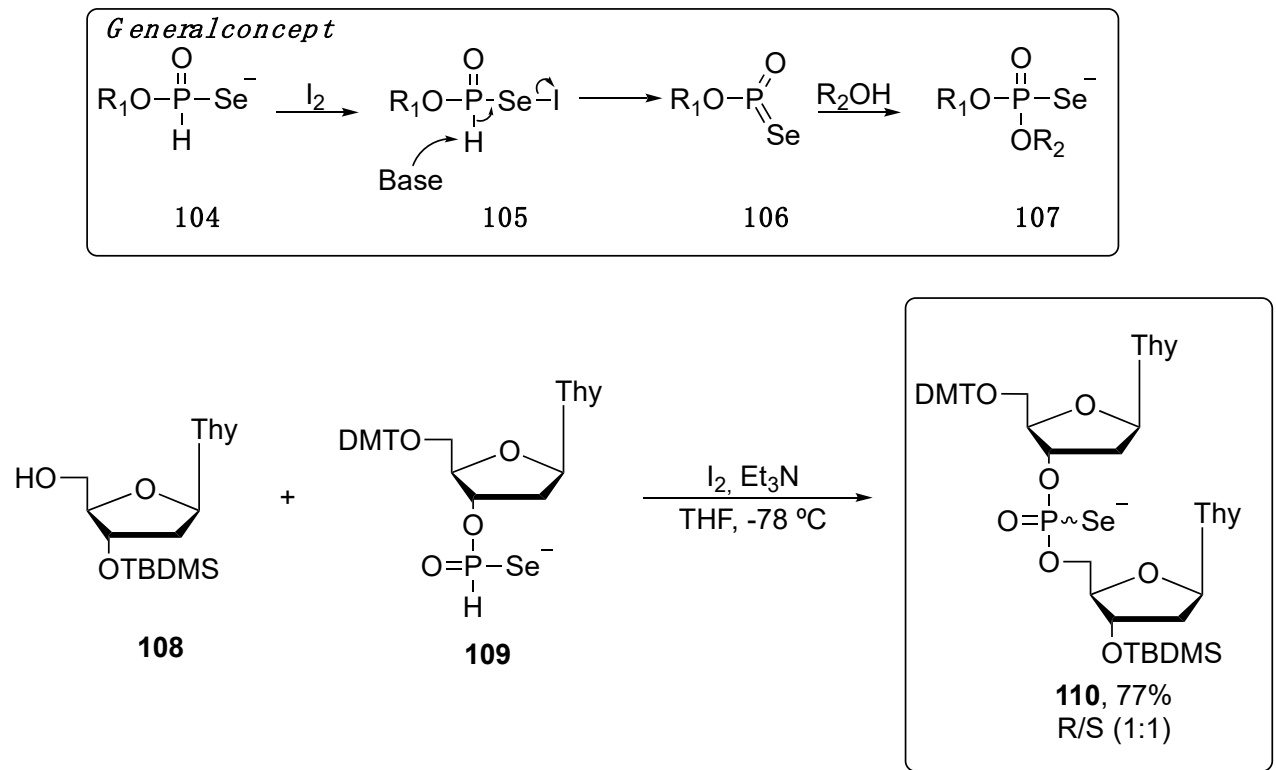

Scheme 18. Oxidative pathway to obtain the phosphoroselenoates.

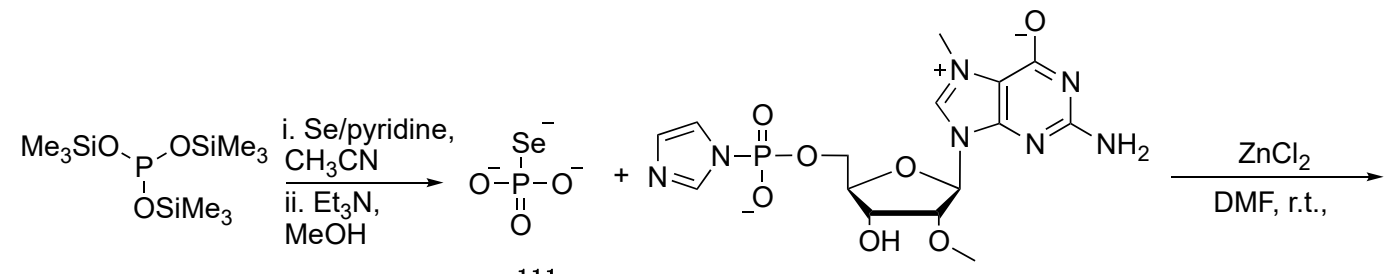

111

112<smiles>CO[C@H]1C[C@H](O)[C@@H](COP(=O)([O-])OP(=O)([O-])[O-])O[C@H]1n1c[n+](C)c2c([O-])nc(N)nc21</smiles>

113<smiles>Nc1nc2c(ncn2C2OC[C@@H](O)[C@@H](OP(=O)([O-])n3ccnc3)O2)c(=O)[nH]1</smiles>

114

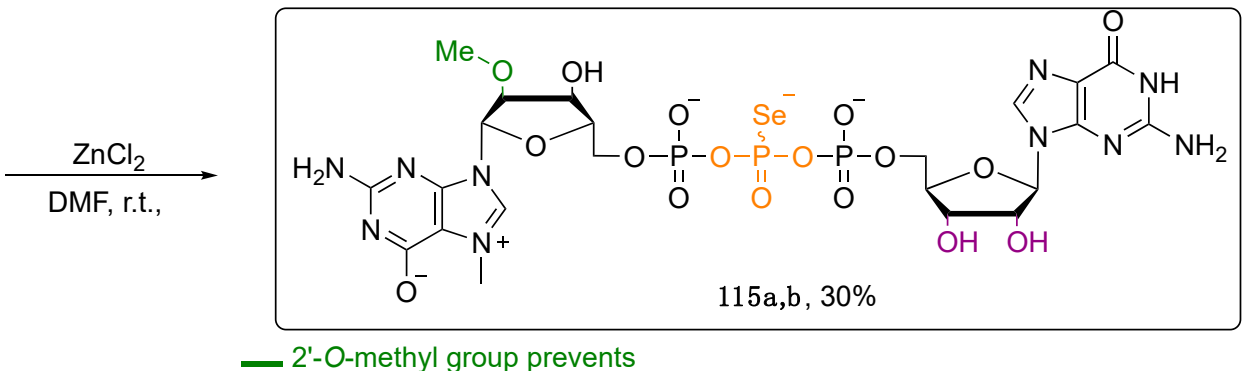

"reverse" incorporation into mRNA

_ Phosphoroselenoate moiety for enzymatic resistence and use in X-ray crystallography

Site of initiation of mRNA transcription by bacteriophage RNA polymerase

Scheme 19. Pathway to obtain the asymmetric phosphoroselenoates $\mathbf{1 1 5}$. 


\section{Se-Nucleosides}

\subsection{Selenium in the Sugar Backbone}

Selenium-containing nucleosides are conceived as the next generation of nucleosides that may serve as starting point for the development of antiviral and anticancer drugs [97-105]. Indeed, the modification of the furanose ring has resulted in many marketed drugs [106]. To the best of our knowledge, the most recent example of $4^{\prime}$-selenonucleoside synthesis was reported in 2019 by Lee and co-workers, who described a procedure to obtain pyrimidine and purine $4^{\prime}$-selenonucleosides meant to act as anti-HCV agents [107].

As reported in Scheme 20, the authors have chosen the 2-C-methyl-D-ribono- $\gamma$-lactone 116 as starting material that, in a three steps telescopic reaction, was converted into the protected lactone 117 with an inverted configuration at the C-4. In the next step, $\mathbf{1 1 7}$ was protected at the primary alcohol with TBDPSCl, generating the intermediate 118, which was subjected to a ring-opening reaction under reductive conditions to give 119. In the sequence, the diol 119 was activated as mesylate and subjected to double nucleophilic substitution with freshly prepared $\mathrm{Na}_{2} \mathrm{Se}$, leading to $\mathbf{1 2 1}$ in fairly good overall yield.

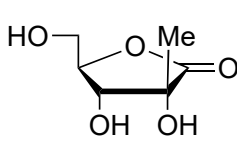

116 i. Acetone, $\mathrm{H}_{2} \mathrm{SO}_{4}, \mathrm{CuSO}_{4}$

$\underset{\text { iii. } \mathrm{KOH} \text {, dioxane } / \mathrm{H}_{2} \mathrm{O}}{\stackrel{\text { ii. }}{\longrightarrow}}$

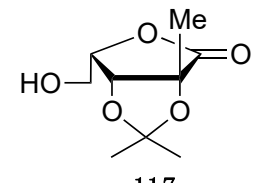

117

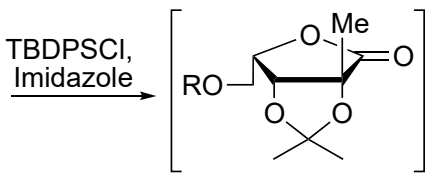

$118 \mathrm{R}=\mathrm{TBDPS}$

$\mathrm{LiBH}_{4}$

Ether, $\mathrm{THF} / \mathrm{H}_{2} \mathrm{O}$
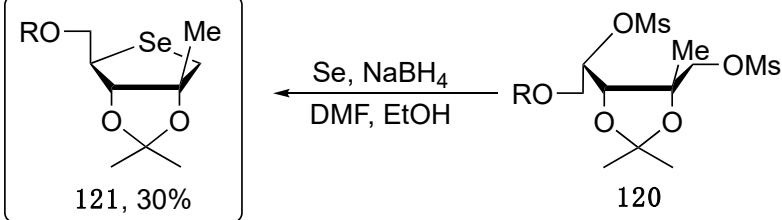

$\frac{\mathrm{MsCl}, \mathrm{Et}_{3} \mathrm{~N}}{\mathrm{CH}_{2} \mathrm{Cl}_{2}}$

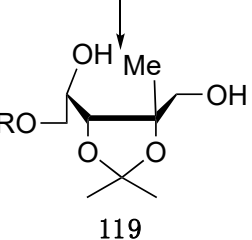

Scheme 20. Synthetic pathway to obtain the selenosugar 121.

With the protected selenosugar synthon 121 in hands, it was converted in both pyrimidines and purines nucleosides. The pyrimidine analogues 124 were prepared converting the selenosugars into a glycosyl-donor (122) and then decorated with the base through the Pummerer reaction [108], affording the compounds 123, which were deprotected under acidic conditions. The target purine compound 128 was prepared converting the synthon 121 into the acetoxyl derivative 125, through a Lewis acid catalyzed Vorbrüggen condensation. Compound 125 was then functionalized with 6-chloropurine, deprotected and aminated at the C-6, affording the target selenosugar 128 (Scheme 21).

In the same work, the authors converted purine and pyrimidine derivatives into phosphoramidate prodrugs, in order to obtain products more likely to have anti-HCV activity. Unfortunately, none of the synthesized compounds showed appreciable antiviral activity.

The big issue associated to the replacement of oxygen with selenium in the furanose ring is that the resulting nucleoside cannot be converted into the corresponding nucleotide because the cellular kinase is sterically hindered by the presence of the bulky selenium with its $4 \mathrm{p}$ orbitals, and the phosphorylation at the $5^{\prime}$ position is hampered $[99,100]$. As a result, such compounds lack biological activity. Among the exceptions, a selenonucleoside (LJ-2618) developed by Lee and colleagues, and biologically profiled in 2018, showed antitumoral potential in vivo and in vitro against paclitaxel-resistant prostate cancer cells. The plausible mechanisms by which LJ-2618 inhibits the growth of cancer cells may be a Skp2-dependent p27 stabilization [109]. 


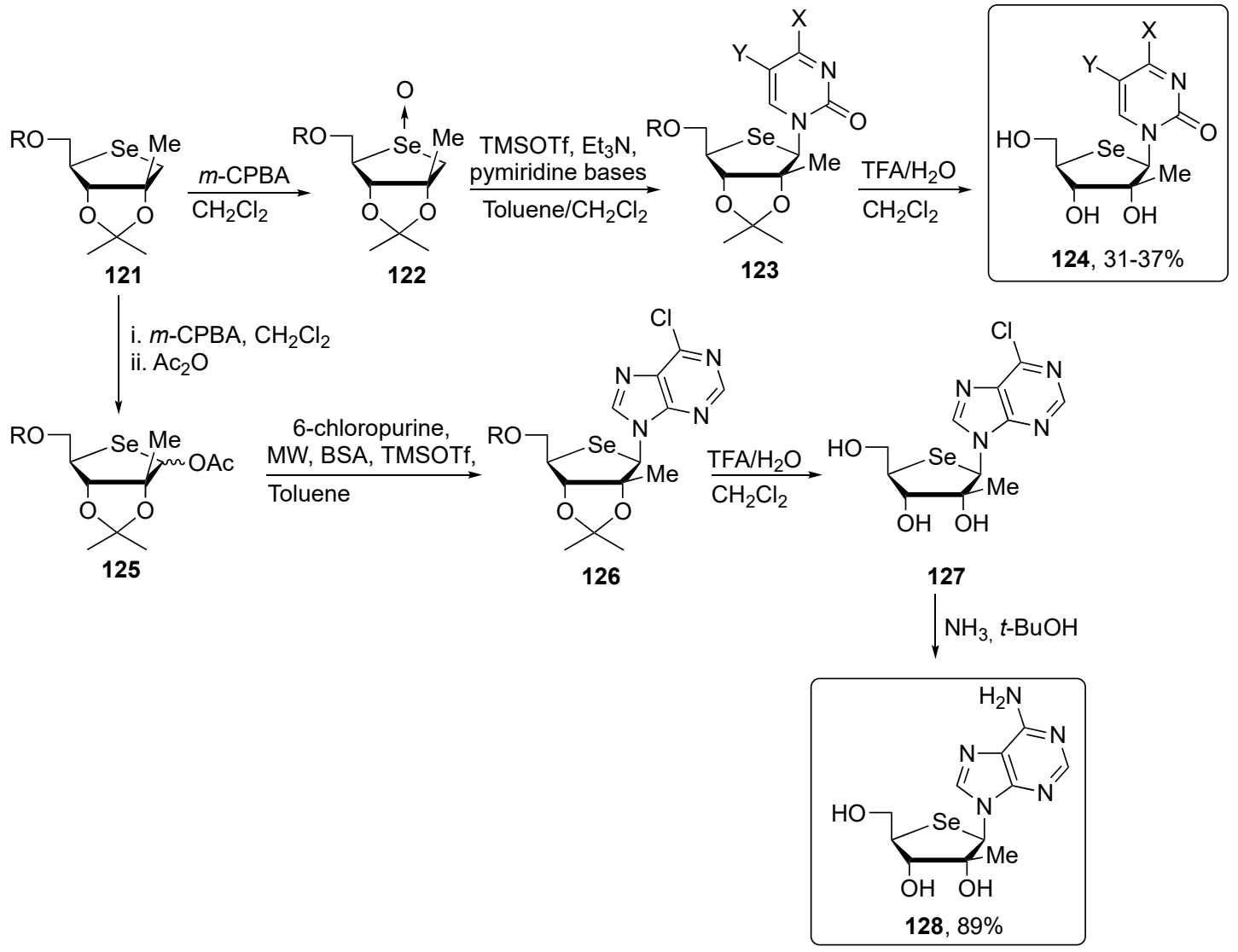

Scheme 21. Synthetic pathway to obtain the selenosugars 124 and $\mathbf{1 2 8 .}$

In order to relieve the steric clash which prevents the cellular phosphorylation, Sahu and co-workers developed a synthetic route to obtain one carbon homologue of $4^{\prime}$-selenonucleosides, namely $5^{\prime}$-homo$4^{\prime}$-selenonucleosides with improved antiviral activity, thus better substrates of cellular kinases when compared to the regular $4^{\prime}$-selenonucleosides. The synthetic route, depicted in Scheme 22, started with the Wittig reaction on the 2,3-O-isopropylidene-L-erythrofuranose $\mathbf{1 2 9}$, followed by the activation of the $\mathrm{OH}$ group as mesylate, affording $\mathbf{1 3 0}$ in a mixture with its $E$-isomer. In the presence of sodium selenide, 130 undergoes concomitant mesyl displacement and intramolecular Se-Michael addition, affording 131 in good yield but as a D/L mixture. Smartly, to isolate the target $\mathrm{D}$ compound $131 \mathrm{a}$, the $\mathrm{D} / \mathrm{L}$ mixture was hydrolyzed with aqueous TFA and then treated with 2,2-dimethoxypropane in the presence of $\mathrm{p}$ - $\mathrm{TsOH}$. In this way, the undesired L diasteroisomer was separated and discarded as the lactone 132. In the same article, efforts were made to shift the stereoselectivity toward the D-isomer, by placing bulky groups such as TBS or TBDPS on the $2^{\prime}$ and $3^{\prime}$ positions of the starting sugar obtaining the target D compound in fourfold excess with respect to the undesired one [110].

With the desired selenosugar 131a in hands, the target carbon chain-extended nucleosides $\mathbf{1 3 6}$ and 139 were prepared by an initial lithium aluminum hydride reduction of the ester and protection with the tert-butyldiphenylsilyl group (TBDPS) yielding compound 133 that was converted into the key glycosyl-donor 134 by oxidation with $m$-CPBA. The intermediate 134 was condensed with the uracil base, and finally deprotected to afford $\mathbf{1 3 6}$ or, alternatively, it reacted with acetic anhydride to give the key synthon 137 , that was condensed with silylated chloropurine and finally deprotected to obtain the compound 139 (Scheme 23). The biological evaluation of compounds 136 and 139 clearly revealed that the homologation beneficially influenced the pharmacological properties, indeed they were far more potent than the corresponding $4^{\prime}$ selenonucleosides when tested against human herpes simplex virus (HSV-1). Indeed 5'-homo-4'-selenonucleosides 136 and 139 displayed anti-HSV-1 activity in the low 
micromolar range $\left(\mathrm{EC}_{50}=2.3\right.$ and $2.9 \mu \mathrm{M}$, respectively) whereas the corresponding 4 '-selenonucleosides were completely inactive [110].

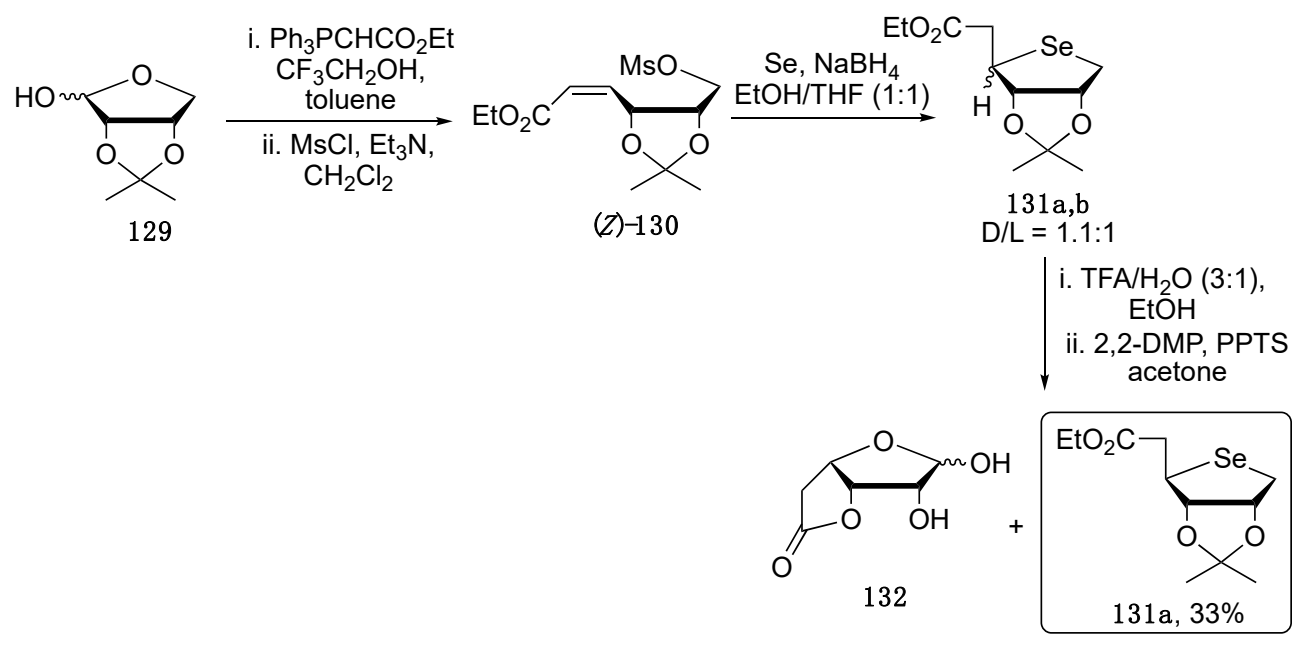

Scheme 22. Synthetic pathway to obtain the key selenosugar intermediate 131a.
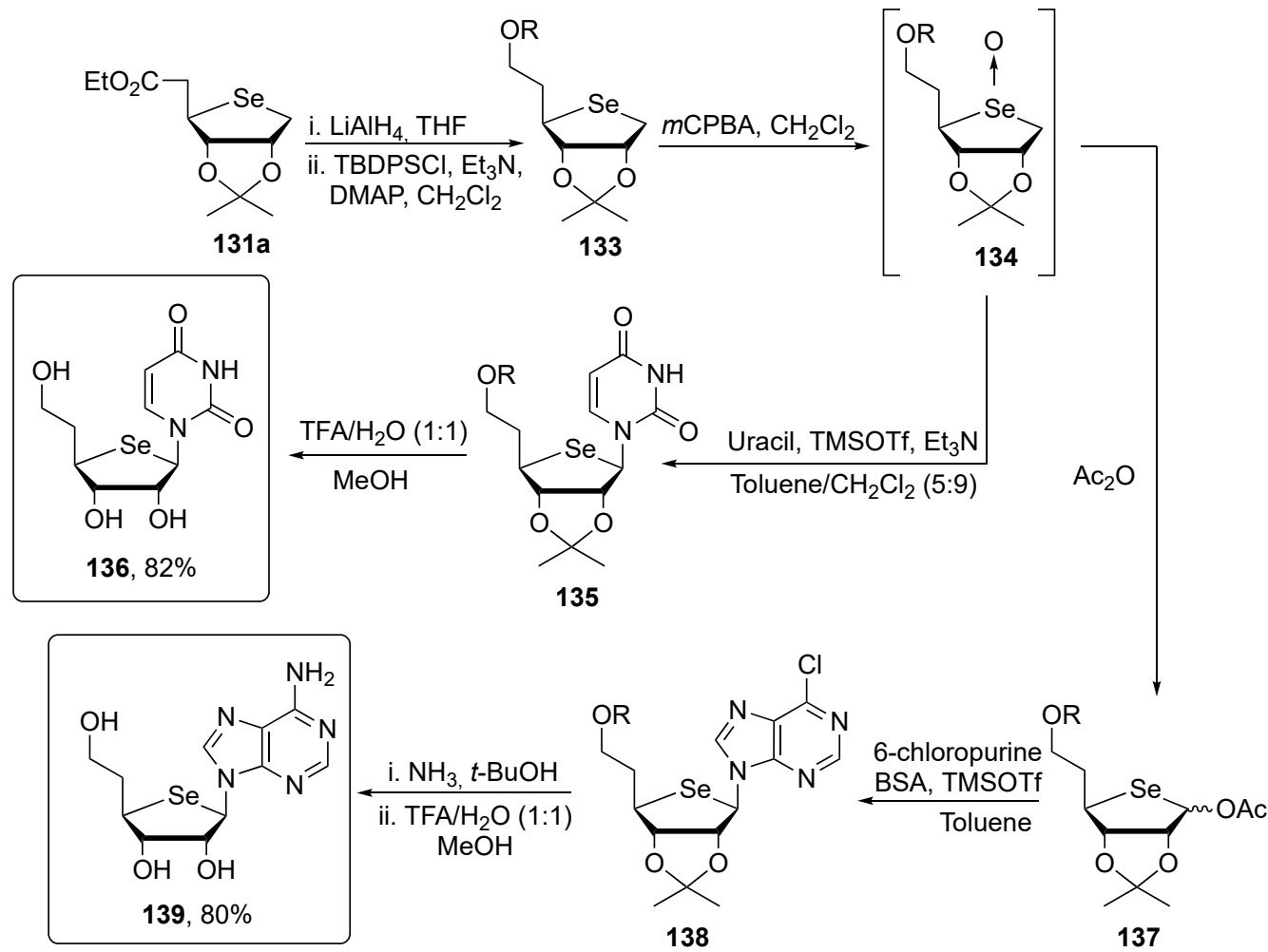

Scheme 23. Synthetic pathway to obtain the 5'-homo-4' selenonucleosides 136 and 139.

\subsection{Selenium in the Nucleobase}

Nucleosides bearing Se-containing bases were prepared and incorporated in oligonucleotides in order to study the pairing capabilities of the strains. One pioneering example is the one reported by Huang et al., who prepared 2-Se-uridine, its incorporation into oligonucleotides, and the investigation of their pairing capabilities [111].

For the synthesis of the desired RNA oligonucleotide incorporating the selenouridine nucleoside, the authors used as starting material the sulfur-containing nucleobase nucleoside 140, that was methylated to promote the substitution reaction with the $\mathrm{NaSeH}$, generated in situ, to obtain the seleno-uridine 
nucleoside 142. Successively, the $\mathrm{C}-2 \mathrm{OH}$ group was protected as TBDMS in the derivative 143, unfortunately with low chemoselectivity. The selone functional group was then functionalized with a cyanoethyl moiety that permitted the successive incorporation into the nascent RNA oligonucleotide 146, through solid phase synthesis (Scheme 24).

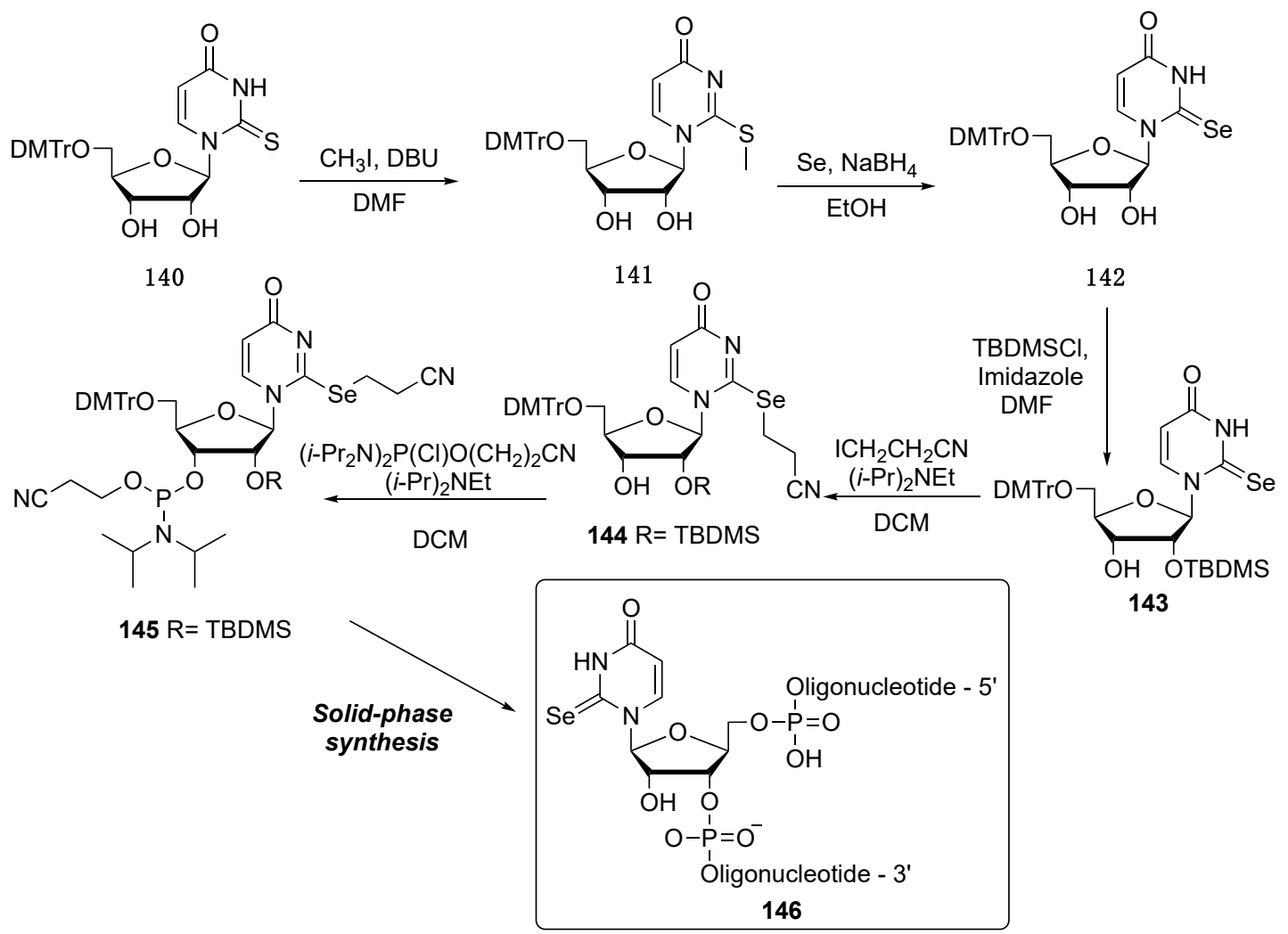

Scheme 24. Synthetic pathway to obtain selenouridine-containing oligonucleotides.

Additionally, Braga contributed to this field by preparing uridine derivatives bearing chalcogen in the C-5 position [112], while Knapp reported an electrophilic aromatic selenylation for the synthesis of 5-uridinyl derivatives then tested for their ability to inhibit malarial orotate phosphoribosyltransferase, a key enzyme in the Plasmodium falciparum life cycle [113].

Examples of the selenium incorporation into purine nucleobases can be found in the works of Huang and co-workers. They prepared compound 150, useful for investigating nucleoside transportation, nucleic acid-protein interaction, and nucleic acid folding, and studied the optical properties as well as its crystal structure $[114,115]$. The preparation entails first the introduction of the cianoethylselenyl moiety into the purine scaffold by aromatic nucleophilic displacement with cianoethylselenol, prepared in situ through the reduction of the corresponding diselenide. Compound $\mathbf{1 4 8}$ was then converted into the target selenonucleoside $\mathbf{1 5 0}$ via a two steps deprotection (Scheme 25).

Despite the advantages offered by the introduction of Se-containing nucleotides into nucleic acids, their synthesis is often complicated by the preparation of the selenium-containing nucleobase. As shown in Scheme 24, at least five steps are needed for the preparation of Se-uridine, with low overall yield. In an attempt to solve this issue, in 2019 Huang's group proposed a new, biocatalytic method to obtain selenonucleosides [116]. This new strategy entails the combined action of two enzymes: pyrimidine nucleoside phosphorylase from Thermus thermophilus (TtPyNP), and purine nucleoside phosphorylase from Geobacillus thermoglucosidasius (GtPNP), which are involved in a transglycosilation reaction. Pyrimidine derivatives were prepared using TtPyNP as enzyme and urididine as furanose donor and a 1:5 molar ratio of selenium-containing nucleobases in phosphate buffer, while the purine 
derivatives were achieved through the tandem action of both TtPyNP and GtPNP (Scheme 26). Of course, the reactions have been carried out in aqueous solution at $60^{\circ} \mathrm{C}$ without the need of organic solvents.

Noteworthy, the resulting nucleotides being negatively charged, all the reactions were followed by capillary electrophoresis analysis.

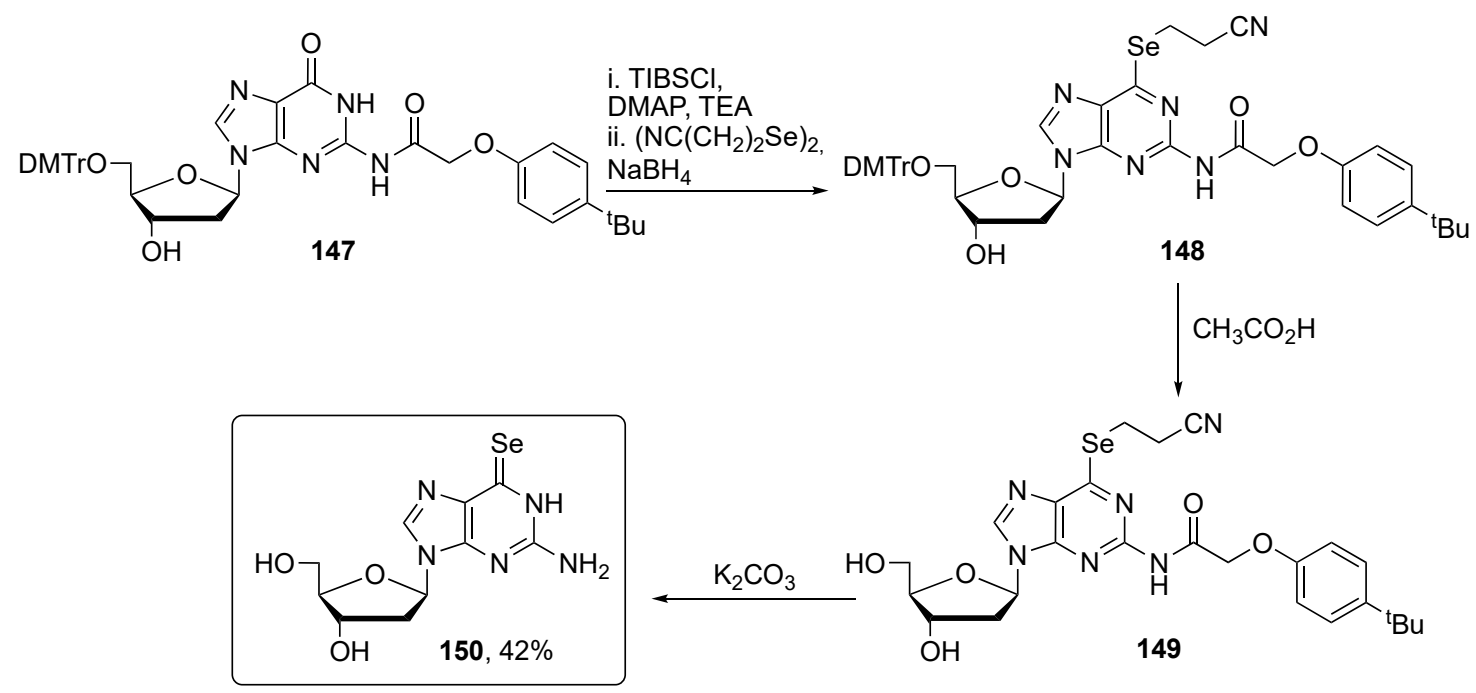

Scheme 25. Synthetic pathway to obtain selenoguanine.
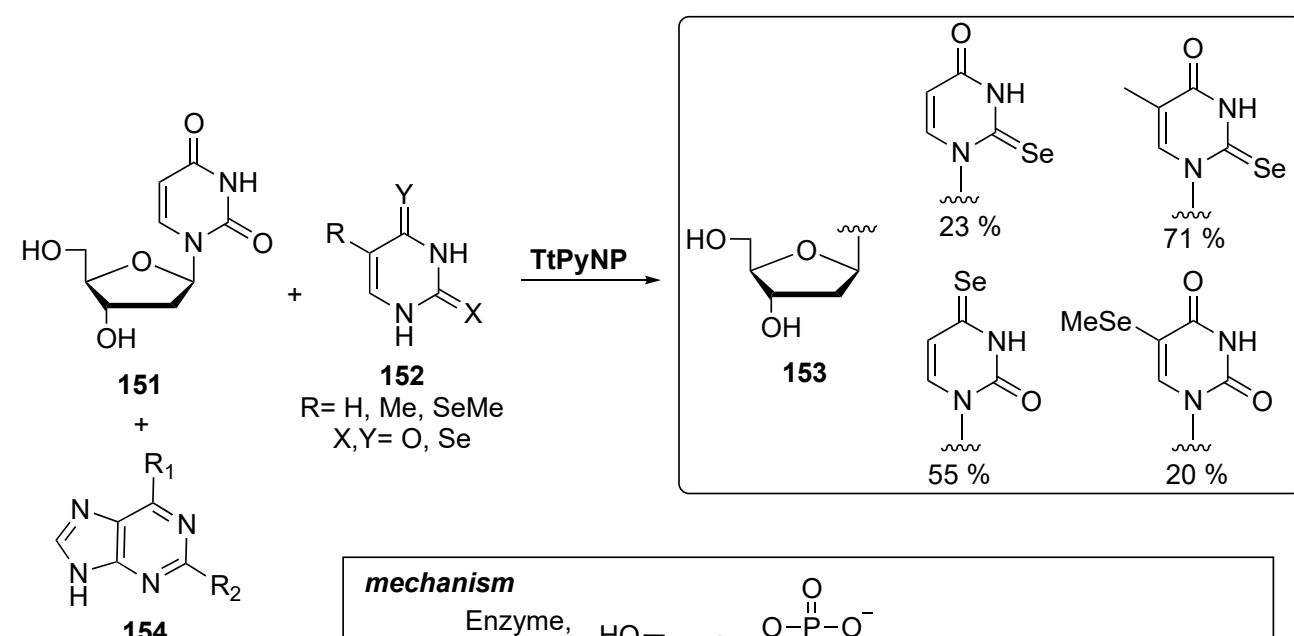

$\mathrm{R}_{1}=\mathrm{H}, \mathrm{SeH}$

$\mathrm{R}_{2}=\mathrm{H}, \mathrm{NH}_{2}$

TtPyNP,

GtPNP
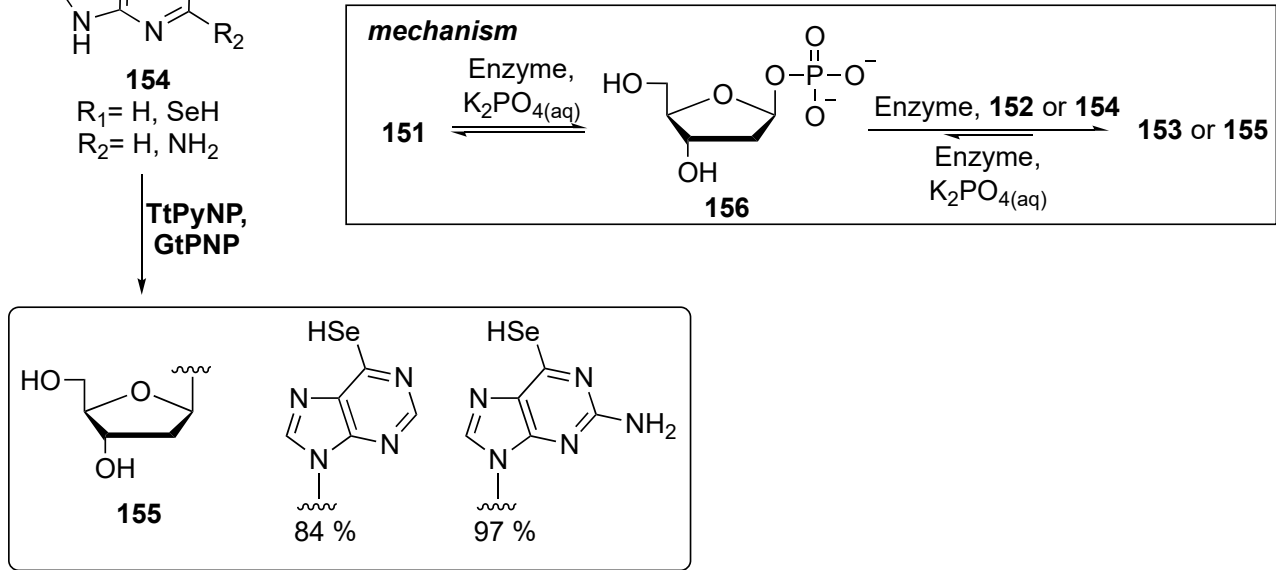

Scheme 26. Biocatalytic approach for the synthesis of selenonucleosides. 


\section{Conclusions}

In this minireview, the selenosugars and the selenosugar-containing classes of compounds were analyzed in order to give fruitful insights to those interested in this research field or who are just approaching it. Different synthetic pathways were analyzed highlighting, where possible, the pros and cons and suggesting useful alternatives.

SeTal, compound 20, is a clear example of an organoselenium compound endowed with antioxidant activity not only in vitro but also in vivo thanks to its water-solubility, which makes it suited for such kinds of studies. Selenonucleosides in which selenium is embedded in the sugar ring structure do display sufficient water-solubility but their biological activity is poor due to the lack of activation by cellular kinase. This issue was partially relieved by the synthesis of Se-homonucleosides. Finally, selenonucleosides were also detailed from a synthetic and applicative standpoint. In the author's opinion, the spread of knowledge regarding this specific research field could help researchers to find solutions for the problem of the low aqueous-solubility, which hampers the actual clinical exploitability of many organoselenium compounds.

Author Contributions: L.S., F.M. (Francesca Mangiavacchi), C.S., E.J.L. and F.M. (Francesca Marini) conceived the review; all the authors contributed selecting and analyzing the literature; writing-original draft preparation, F.M. (Francesca Mangiavacchi), I.D.L., I.F.C.D., P.G. and L.S.; writing-review and editing, L.B., O.R., C.S. E.J.L., F.M. (Francesca Marini), L.S. and M.P. revised the manuscript after referees' comments. All authors have read and agreed to the published version of the manuscript.

Funding: This research received no external funding.

Acknowledgments: This manuscript is part of the disseminative activity of the International Network Selenium, Sulfur, Redox and Catalysis (SeSRedCat). Francesca Mangiavacchi thanks the committee of ICCST-14 (the 14th International Conference on the Chemistry of Selenium and Tellurium) and MDPI to being awarded with a fully waived publication as the best short oral communication.

Conflicts of Interest: The authors declare no conflict of interest.

\section{References}

1. Lenardão, E.J.; Santi, C.; Sancineto, L. New Frontiers in Organoselenium Compounds; Springer International Publishing: Cham, Switzerland, 2018; ISBN 978-3-319-92404-5.

2. Santi, C.; Marini, F.; Lenardão, E.J. Synthetic Advances on Bioactive Selenium CompoundsChapter 2: Looking Beyond the Traditional Idea of Glutathione Peroxidase Mimics as Antioxidants. In Organoselenium Compounds in Biology and Medicine; Royal Society of Chemistry: Cambridge, UK, 2017; pp. 35-76.

3. Spengler, G.; Kincses, A.; Mosolygó, T.; Marć, M.A.; Nové, M.; Gajdács, M.; Sanmartín, C.; McNeil, H.E.; Blair, J.M.A.; Domínguez-Álvarez, E. Domínguez-Álvarez Antiviral, Antimicrobial and Antibiofilm Activity of Selenoesters and Selenoanhydrides. Molecules 2019, 24, 4264. [CrossRef] [PubMed]

4. Geoffrion, L.D.; Hesabizadeh, T.; Medina-Cruz, D.; Kusper, M.; Taylor, P.; Vernet-Crua, A.; Chen, J.; Ajo, A.; Webster, T.J.; Guisbiers, G. Naked Selenium Nanoparticles for Antibacterial and Anticancer Treatments. ACS Omega 2020, 5, 2660-2669. [CrossRef] [PubMed]

5. Angeli, A.; Pinteala, M.; Maier, S.S.; Simionescu, B.C.; Milaneschi, A.; Abbas, G.; del Prete, S.; Capasso, C.; Capperucci, A.; Tanini, D.; et al. Evaluation of Thio- and Seleno-Acetamides Bearing Benzenesulfonamide as Inhibitor of Carbonic Anhydrases from Different Pathogenic Bacteria. Int. J. Mol. Sci. 2020, 21, 598. [CrossRef] [PubMed]

6. Perfileva, A.I.; Nozhkina, O.A.; Graskova, I.A.; Dyakova, A.V.; Pavlova, A.G.; Aleksandrova, G.P.; Klimenkov, I.V.; Sukhov, B.G.; Trofimov, B.A. Selenium Nanocomposites Having Polysaccharid Matrices Stimulate Growth of Potato Plants in Vitro Infected with Ring Rot Pathogen. Dokl. Biol. Sci. 2019, 489, 184-188. [CrossRef] [PubMed]

7. Bartolini, D.; Sancineto, L.; Fabro de Bem, A.; Tew, K.D.; Santi, C.; Radi, R.; Toquato, P.; Galli, F. Selenocompounds in Cancer Therapy: An Overview. In Advances in Cancer Research; Academic Press: Cambridge, MA, USA, 2017; Volume 136, pp. 259-302, ISBN 9780128120163. 
8. Müller, A.; Cadenas, E.; Graf, P.; Sies, H. A novel biologically active seleno-organic compound-1. Glutathione peroxidase-like activity in vitro and antioxidant capacity of PZ 51 (Ebselen). Biochem. Pharmacol. 1984, 33, 3235-3239. [CrossRef]

9. Krasowska, D.; Iraci, N.; Santi, C.; Drabowicz, J.; Cieslak, M.; Kaźmierczak-Barańska, J.; Palomba, M.; Królewska-Golińska, K.; Magiera, J.; Sancineto, L. Diselenides and Benzisoselenazolones as Antiproliferative Agents and Glutathione-S-Transferase Inhibitors. Molecules 2019, 24, 2914. [CrossRef]

10. Domínguez-Álvarez, E.; Gajdács, M.; Spengler, G.; Palop, J.A.; Marć, M.A.; Kieć-Kononowicz, K.; Amaral, L.; Molnár, J.; Jacob, C.; Handzlik, J.; et al. Identification of selenocompounds with promising properties to reverse cancer multidrug resistance. Bioorg. Med. Chem. Lett. 2016, 26, 2821-2824. [CrossRef]

11. Kim, C.; Lee, J.; Park, M.-S. Synthesis of new diorganodiselenides from organic halides: Their antiproliferative effects against human breast cancer MCF-7 cells. Arch. Pharm. Res. 2015, 38, 659-665. [CrossRef]

12. Pacuła, A.J.; Kaczor, K.B.; Antosiewicz, J.; Janecka, A.; Długosz, A.; Janecki, T.; Wojtczak, A.; Ścianowski, J. New Chiral Ebselen Analogues with Antioxidant and Cytotoxic Potential. Molecules 2017, 22, 492. [CrossRef]

13. Sarma, B.K.; Mugesh, G. Antioxidant Activity of the Anti-Inflammatory Compound Ebselen: A Reversible Cyclization Pathway via Selenenic and Seleninic Acid Intermediates. Chem. A Eur. J. 2008, 14, 10603-10614. [CrossRef]

14. Nogueira, C.W.; Quinhones, E.B.; Jung, E.A.C.; Zeni, G.; Rocha, J.B.T. Anti-inflammatory and antinociceptive activity of diphenyl diselenide. Inflamm. Res. 2003, 52, 56-63. [CrossRef] [PubMed]

15. Pinto Brod, L.M.; Fronza, M.G.; Vargas, J.P.; Lüdtke, D.S.; Luchese, C.; Wilhelm, E.A.; Savegnago, L. Involvement of monoaminergic system in the antidepressant-like effect of (octylseleno)-xylofuranoside in the mouse tail suspension test. Prog. Neuro-Psychopharmacol. Biol. Psychiatry 2016, 65, 201-207. [CrossRef] [PubMed]

16. Singh, N.; Halliday, A.C.; Thomas, J.M.; Kuznetsova, O.V.; Baldwin, R.; Woon, E.C.Y.; Aley, P.K.; Antoniadou, I.; Sharp, T.; Vasudevan, S.R.; et al. A safe lithium mimetic for bipolar disorder. Nat. Commun. 2013, 4, 1332. [CrossRef] [PubMed]

17. Sancineto, L.; Piccioni, M.; De Marco, S.; Pagiotti, R.; Nascimento, V.; Braga, A.L.; Santi, C.; Pietrella, D. Diphenyl diselenide derivatives inhibit microbial biofilm formation involved in wound infection. BMC Microbiol. 2016, 16, 220. [CrossRef] [PubMed]

18. Chiou, J.; Wan, S.; Chan, K.-F.; So, P.-K.; He, D.; Chan, E.W.; Chan, T.; Wong, K.; Tao, J.; Chen, S. Ebselen as a potent covalent inhibitor of New Delhi metallo- $\beta$-lactamase (NDM-1). Chem. Commun. 2015, 51, 9543-9546. [CrossRef] [PubMed]

19. Macegoniuk, K.; Grela, E.; Palus, J.; Rudzińska-Szostak, E.; Grabowiecka, A.; Biernat, M.; Berlicki, Ł. 1,2-Benzisoselenazol-3(2H)-one Derivatives As a New Class of Bacterial Urease Inhibitors. J. Med. Chem. 2016, 59, 8125-8133. [CrossRef]

20. Sancineto, L.; Mariotti, A.; Bagnoli, L.; Marini, F.; Desantis, J.; Iraci, N.; Santi, C.; Pannecouque, C.; Tabarrini, O. Design and Synthesis of DiselenoBisBenzamides (DISeBAs) as Nucleocapsid Protein 7 (NCp7) Inhibitors with anti-HIV Activity. J. Med. Chem. 2015, 58, 9601-9614. [CrossRef]

21. Sancineto, L.; Iraci, N.; Tabarrini, O.; Santi, C. NCp7: Targeting a multitasking protein for next-generation anti-HIV drug development part 1: Covalent inhibitors. Drug Discov. Today 2018, 23, 260-271. [CrossRef]

22. Iraci, N.; Tabarrini, O.; Santi, C.; Sancineto, L. NCp7: Targeting a multitask protein for next-generation anti-HIV drug development part 2. Noncovalent inhibitors and nucleic acid binders. Drug Discov. Today 2018, 23, 687-695. [CrossRef]

23. Jin, Z.; Du, X.; Xu, Y.; Deng, Y.; Liu, M.; Zhao, Y.; Zhang, B.; Li, X.; Zhang, L.; Peng, C.; et al. Structure of Mpro from SARS-CoV-2 and discovery of its inhibitors. Nature 2020, 582, 289-293. [CrossRef]

24. Lipinski, C.A. Poor Aqueous Solubility-An Industry Wide Problem in ADME Screening. Am. Pharm. Rev. 2002, 5, 82-85.

25. Lipinski, C.A.; Lombardo, F.; Dominy, B.W.; Feeney, P.J. Experimental and computational approaches to estimate solubility and permeability in drug discovery and development settings. Adv. Drug Deliv. Rev. 2001, 46, 3-26. [CrossRef]

26. Davies, M.J.; Schiesser, C.H. 1,4-Anhydro-4-seleno-D-talitol (SeTal): A remarkable selenium-containing therapeutic molecule. New J. Chem. 2019, 43, 9759-9765. [CrossRef] 
27. Lucas, M.A.; Nguyen, O.T.K.; Schiesser, C.H.; Zheng, S.-L. Preparation of 5-Selenopentopyranose Sugars from Pentose Starting Materials by Samarium(II) Iodide or (Phenylseleno)formate Mediated Ring Closures. Tetrahedron 2000, 56, 3995-4000. [CrossRef]

28. Storkey, C.; Davies, M.J.; White, J.M.; Schiesser, C.H. Synthesis and antioxidant capacity of 5-selenopyranose derivatives. Chem. Commun. 2011, 47, 9693. [CrossRef] [PubMed]

29. Storkey, C.; Pattison, D.I.; White, J.M.; Schiesser, C.H.; Davies, M.J. Preventing Protein Oxidation with Sugars: Scavenging of Hypohalous Acids by 5-Selenopyranose and 4-Selenofuranose Derivatives. Chem. Res. Toxicol. 2012, 25, 2589-2599. [CrossRef] [PubMed]

30. Davies, M.J.; Hawkins, C.L.; Pattison, D.I.; Rees, M.D. Mammalian Heme Peroxidases: From Molecular Mechanisms to Health Implications. Antioxid. Redox Signal. 2008, 10, 1199-1234. [CrossRef] [PubMed]

31. Klebanoff, S.J.; Kettle, A.J.; Rosen, H.; Winterbourn, C.C.; Nauseef, W.M. Myeloperoxidase: A front-line defender against phagocytosed microorganisms. J. Leukoc. Biol. 2013, 93, 185-198. [CrossRef] [PubMed]

32. Sies, H. Oxidative stress: A concept in redox biology and medicine. Redox Biol. 2015, 4, 180-183. [CrossRef]

33. Yan, L.-J. Positive oxidative stress in aging and aging-related disease tolerance. Redox Biol. 2014, 2, $165-169$. [CrossRef]

34. Storkey, C.; Pattison, D.I.; Ignasiak, M.T.; Schiesser, C.H.; Davies, M.J. Kinetics of reaction of peroxynitrite with selenium- and sulfur-containing compounds: Absolute rate constants and assessment of biological significance. Free Radic. Biol. Med. 2015, 89, 1049-1056. [CrossRef] [PubMed]

35. Carroll, L.; Pattison, D.I.; Fu, S.; Schiesser, C.H.; Davies, M.J.; Hawkins, C.L. Catalytic oxidant scavenging by selenium-containing compounds: Reduction of selenoxides and N-chloramines by thiols and redox enzymes. Redox Biol. 2017, 12, 872-882. [CrossRef] [PubMed]

36. Ng, H.H.; Leo, C.H.; O'Sullivan, K.; Alexander, S.-A.; Davies, M.J.; Schiesser, C.H.; Parry, L.J. 1,4-Anhydro4-seleno-d-talitol (SeTal) protects endothelial function in the mouse aorta by scavenging superoxide radicals under conditions of acute oxidative stress. Biochem. Pharmacol. 2017, 128, 34-45. [CrossRef] [PubMed]

37. Kötzler, M.P.; Hancock, S.M.; Withers, S.G. Glycosidases: Functions, Families and Folds. In eLS; John Wiley \& Sons, Ltd.: Chichester, UK, 2014.

38. Gerber-Lemaire, S.; Juillerat-Jeanneret, L. Glycosylation Pathways as Drug Targets for Cancer: Glycosidase Inhibitors. Mini-Rev. Med. Chem. 2006, 6, 1043-1052. [CrossRef]

39. Merino-Montiel, P.; López, Ó.; Fernández-Bolaños, J.G. l-Isofucoselenofagomine and derivatives: Dual activities as antioxidants and as glycosidase inhibitors. Tetrahedron 2012, 68, 3591-3595. [CrossRef]

40. Medagama, A.B. Salacia reticulata (Kothala himbutu) revisited; a missed opportunity to treat diabetes and obesity? Nutr. J. 2015, 14, 21. [CrossRef]

41. Stohs, S.J.; Ray, S. Anti-diabetic and Anti-hyperlipidemic Effects and Safety of Salacia reticulata and Related Species. Phyther. Res. 2015, 29, 986-995. [CrossRef]

42. Meigs, J.B. The Genetic Epidemiology of Type 2 Diabetes: Opportunities for Health Translation. Curr. Diab. Rep. 2019, 19, 62. [CrossRef]

43. Morikawa, T.; Akaki, J.; Ninomiya, K.; Kinouchi, E.; Tanabe, G.; Pongpiriyadacha, Y.; Yoshikawa, M.; Muraoka, O. Salacinol and Related Analogs: New Leads for Type 2 Diabetes Therapeutic Candidates from the Thai Traditional Natural Medicine Salacia chinensis. Nutrients 2015, 7, 1480-1493. [CrossRef]

44. Mohan, S.; Pinto, B.M. Towards the elusive structure of kotalanol, a naturally occurring glucosidase inhibitor. Nat. Prod. Rep. 2010, 27, 481. [CrossRef]

45. Mohan, S.; Eskandari, R.; Pinto, B.M. Naturally Occurring Sulfonium-Ion Glucosidase Inhibitors and Their Derivatives: A Promising Class of Potential Antidiabetic Agents. Acc. Chem. Res. 2014, 47, 211-225. [CrossRef]

46. Mohan, S.; Pinto, B.M. Sulfonium-ion glycosidase inhibitors isolated from Salacia species used in traditional medicine, and related compounds. Collect. Czechoslov. Chem. Commun. 2009, 74, 1117-1136. [CrossRef]

47. Mohan, S.; Pinto, B.M. Zwitterionic glycosidase inhibitors: Salacinol and related analogues. Carbohydr. Res. 2007, 342, 1551-1580. [CrossRef] [PubMed]

48. Bischoff, H. Pharmacology of $\alpha$-glucosidase inhibition. Eur. J. Clin. Invest. 2010, 24, 3-10. [CrossRef]

49. Eskandari, R.; Jones, K.; Rose, D.R.; Pinto, B.M. The effect of heteroatom substitution of sulfur for selenium in glucosidase inhibitors on intestinal $\alpha$-glucosidase activities. Chem. Commun. 2011, 47, 9134. [CrossRef] [PubMed] 
50. Johnston, B.D.; Ghavami, A.; Jensen, M.T.; Svensson, B.; Pinto, B.M. Synthesis of Selenium Analogues of the Naturally Occurring Glycosidase Inhibitor Salacinol and Their Evaluation as Glycosidase Inhibitors. J. Am. Chem. Soc. 2002, 124, 8245-8250. [CrossRef]

51. Liu, H.; Sim, L.; Rose, D.R.; Pinto, B.M. A New Class of Glucosidase Inhibitor: Analogues of the Naturally Occurring Glucosidase Inhibitor Salacinol with Different Ring Heteroatom Substituents and Acyclic Chain Extension. J. Org. Chem. 2006, 71, 3007-3013. [CrossRef]

52. Liu, H.; Pinto, B.M. Synthesis of zwitterionic selenonium and sulfonium sulfates from D-mannose as potential glycosidase inhibitors. Can. J. Chem. 2006, 84, 497-505. [CrossRef]

53. Liu, H.; Pinto, B.M. Design and synthesis of selenonium and sulfonium ions related to the naturally occurring glucosidase inhibitor salacinol. Can. J. Chem. 2006, 84, 1351-1362. [CrossRef]

54. Nasi, R.; Sim, L.; Rose, D.R.; Pinto, B.M. New Chain-Extended Analogues of Salacinol and Blintol and Their Glycosidase Inhibitory Activities. Mapping the Active-Site Requirements of Human Maltase Glucoamylase. J. Org. Chem. 2007, 72, 180-186. [CrossRef]

55. Nasi, R.; Sim, L.; Rose, D.R.; Pinto, B.M. Synthesis and glycosidase inhibitory activities of chain-modified analogues of the glycosidase inhibitors salacinol and blintol. Carbohydr. Res. 2007, 342, 1888-1894. [CrossRef] [PubMed]

56. Liu, H.; Pinto, B.M. Efficient synthesis of the glucosidase inhibitor blintol, the selenium analogue of the naturally occurring glycosidase inhibitor salacinol. J. Org. Chem. 2005, 70, 753-755. [CrossRef] [PubMed]

57. Bonner, W.A.; Robinson, A. The Preparation and Properties of Phenyl $\beta$-D-Selenoglucoside and its Tetraacetate. J. Am. Chem. Soc. 1950, 72, 354-356. [CrossRef]

58. Whistler, R.L.; Witczak, Z.J. Carbohydrates Containing Selenium. Heterocycles 1982, 19, 1719. [CrossRef]

59. Mehta, S.; Mario Pinto, B. Phenylselenoglycosides as novel, versatile glycosyl donors. Selective activation over thioglycosides. Tetrahedron Lett. 1991, 32, 4435-4438. [CrossRef]

60. Mehta, S.; Pinto, B.M. Novel glycosidation methodology. The use of phenyl selenoglycosides as glycosyl donors and acceptors in oligosaccharide synthesis. J. Org. Chem. 1993, 58, 3269-3276. [CrossRef]

61. Grice, P.; Ley, S.V.; Pietruszka, J.; Osborn, H.M.I.; Priepke, H.W.M.; Warriner, S.L. A New Strategy for Oligosaccharide Assembly Exploiting Cyclohexane-1,2-diacetal Methodology: An Efficient Synthesis of a High Mannose Type Nonasaccharide. Chem. A Eur. J. 2006, 3, 431-440. [CrossRef]

62. van Well, R.M.; Kärkkäinen, T.S.; Kartha, K.P.R.; Field, R.A. Contrasting reactivity of thioglucoside and selenoglucoside donors towards promoters: Implications for glycosylation stereocontrol. Carbohydr. Res. 2006, 341, 1391-1397. [CrossRef]

63. Buts, L.; Loris, R.; De Genst, E.; Oscarson, S.; Lahmann, M.; Messens, J.; Brosens, E.; Wyns, L.; De Greve, H.; Bouckaert, J. Solving the phase problem for carbohydrate-binding proteins using selenium derivatives of their ligands: A case study involving the bacterial F17-G adhesin. Acta Crystallogr. Sect. D Biol. Crystallogr. 2003, 59, 1012-1015. [CrossRef]

64. Suzuki, T.; Makyio, H.; Ando, H.; Komura, N.; Menjo, M.; Yamada, Y.; Imamura, A.; Ishida, H.; Wakatsuki, S.; Kato, R.; et al. Expanded potential of seleno-carbohydrates as a molecular tool for X-ray structural determination of a carbohydrate-protein complex with single/multi-wavelength anomalous dispersion phasing. Bioorg. Med. Chem. 2014, 22, 2090-2101. [CrossRef]

65. Saino, H.; Ago, H.; Ukita, Y.; Miyano, M. Seleno-detergent MAD phasing of leukotriene C 4 synthase in complex with dodecyl- $\beta$-D-selenomaltoside. Acta Crystallogr. Sect. F Struct. Biol. Cryst. Commun. 2011, 67, 1666-1673. [CrossRef] [PubMed]

66. Di Bussolo, V.; Fiasella, A.; Balzano, F.; Uccello Barretta, G.; Crotti, P. Stereoselective Synthesis of $\beta$-Phenylselenoglycosides from Glycals and Rationalization of the Selenoglycosylation Processes. J. Org. Chem. 2010, 75, 4284-4287. [CrossRef]

67. Chambers, D.J.; Evans, G.R.; Fairbanks, A.J. Elimination reactions of glycosyl selenoxides. Tetrahedron 2004, 60, 8411-8419. [CrossRef]

68. Valerio, S.; Iadonisi, A.; Adinolfi, M.; Ravidà, A. Novel Approaches for the Synthesis and Activation of Thioand Selenoglycoside Donors. J. Org. Chem. 2007, 72, 6097-6106. [CrossRef] [PubMed]

69. Tiwari, P.; Misra, A.K. Indium(I) iodide mediated efficient synthesis of selenoglycosides. Tetrahedron Lett. 2006, 47, 2345-2348. [CrossRef] 
70. Mukherjee, C.; Tiwari, P.; Misra, A.K. Synthesis of thio- and selenoglycosides by cleavage of dichalconides in the presence of zinc/zinc chloride and reaction with glycosyl bromides. Tetrahedron Lett. 2006, 47, 441-445. [CrossRef]

71. Witczak, Z.J.; Czernecki, S. Synthetic Applications of Selenium-Containing Sugars. In Advances in Carbohydrate Chemistry and Biochemistry; Elsevier: Amsterdam, The Netherlands, 1998; pp. 143-199.

72. Frenzel, H.; Nuhn, P.; Wagner, G. Über Thiophenol- und Selenophenol- $\alpha$-D-glucopyranoside. Arch. Pharm. (Weinh.) 1969, 302, 62-72. [CrossRef]

73. Sancineto, L.; Palomba, M.; Bagnoli, L.; Marini, F.; Santi, C. Advances in Electrophilic Organochalcogen Reagents. Curr. Org. Chem. 2015, 20, 122-135. [CrossRef]

74. Santi, C.; Tomassini, C.; Sancineto, L. Organic diselenides: Versatile reagents, precursors, and intriguing biologically active compounds. CHIMIA (Aarau) 2017, 71. [CrossRef]

75. Braga, H.C.; Stefani, H.A.; Paixão, M.W.; Santos, F.W.; Lüdtke, D.S. Synthesis of 5'-seleno-xylofuranosides. Tetrahedron 2010, 66, 3441-3446. [CrossRef]

76. Braga, H.C.; Wouters, A.D.; Zerillo, F.B.; Lüdtke, D.S. Synthesis of seleno-carbohydrates derived from d-galactose. Carbohydr. Res. 2010, 345, 2328-2333. [CrossRef] [PubMed]

77. Kumar, A.A.; Illyés, T.Z.; Kövér, K.E.; Szilágyi, L. Convenient syntheses of 1,2-trans selenoglycosides using isoselenuronium salts as glycosylselenenyl transfer reagents. Carbohydr. Res. 2012, 360, 8-18. [CrossRef] [PubMed]

78. Suzuki, T.; Komura, N.; Imamura, A.; Ando, H.; Ishida, H.; Kiso, M. A facile method for synthesizing selenoglycosides based on selenium-transfer to glycosyl imidate. Tetrahedron Lett. 2014, 55, 1920-1923. [CrossRef]

79. Guan, Y.; Townsend, S.D. Metal-Free Synthesis of Unsymmetrical Organoselenides and Selenoglycosides. Org. Lett. 2017, 19, 5252-5255. [CrossRef]

80. Knapp, S.; Darout, E. New Reactions of Selenocarboxylates. Org. Lett. 2005, 7, 203-206. [CrossRef] [PubMed]

81. Kawai, Y.; Ando, H.; Ozeki, H.; Koketsu, M.; Ishihara, H. A Facile Method for $\beta$-Selenoglycoside Synthesis Using $\beta$-p-Methylbenzoyl Selenoglycoside as the Selenating Unit. Org. Lett. 2005, 7, 4653-4656. [CrossRef] [PubMed]

82. Boutureira, O.; Bernardes, G.J.L.; Fernández-González, M.; Anthony, D.C.; Davis, B.G. SelenenylsulfideLinked Homogeneous Glycopeptides and Glycoproteins: Synthesis of Human "Hepatic Se Metabolite A". Angew. Chem. Int. Ed. 2012, 51, 1432-1436. [CrossRef]

83. Gamblin, D.P.; Garnier, P.; van Kasteren, S.; Oldham, N.J.; Fairbanks, A.J.; Davis, B.G. Glyco-SeS: Selenenylsulfide-Mediated Protein Glycoconjugation-A New Strategy in Post-Translational Modification. Angew. Chem. Int. Ed. 2004, 43, 828-833. [CrossRef]

84. Ahn, S.J.; Koketsu, M.; Ishihara, H.; Lee, S.M.; Ha, S.K.; Lee, K.H.; Kang, T.H.; Kima, S.Y. Regulation of Melanin Synthesis by Selenium-Containing Carbohydrates. Chem. Pharm. Bull. (Tokyo) 2006, 54, 281-286. [CrossRef]

85. Yamago, S.; Yamada, T.; Hara, O.; Ito, H.; Mino, Y.; Yoshida, J. A New, Iterative Strategy of Oligosaccharide Synthesis Based on Highly Reactive $\beta$-Bromoglycosides Derived from Selenoglycosides. Org. Lett. 2001, 3, 3867-3870. [CrossRef]

86. Yamago, S.; Yamada, T.; Ito, H.; Hara, O.; Mino, Y.; Yoshida, J. Combinatorial Synthesis of an Oligosaccharide Library by Using $\beta$-Bromoglycoside-Mediated Iterative Glycosylation of Selenoglycosides: Rapid Expansion of Molecular Diversity with Simple Building Blocks. Chem. A Eur. J. 2005, 11, 6159-6174. [CrossRef] [PubMed]

87. Affeldt, R.F.; Braga, H.C.; Baldassari, L.L.; Lüdtke, D.S. Synthesis of selenium-linked neoglycoconjugates and pseudodisaccharides. Tetrahedron 2012, 68, 10470-10475. [CrossRef]

88. Fournière, V.; Cumpstey, I. Synthesis of non-glycosidically linked selenoether pseudodisaccharides. Tetrahedron Lett. 2010, 51, 2127-2129. [CrossRef]

89. Cumpstey, I.; Ramstadius, C.; Akhtar, T.; Goldstein, I.J.; Winter, H.C. Non-Glycosidically Linked Pseudodisaccharides: Thioethers, Sulfoxides, Sulfones, Ethers, Selenoethers, and Their Binding to Lectins. Eur. J. Org. Chem. 2010, 2010, 1951-1970. [CrossRef]

90. Cumpstey, I. Neodisaccharide diglycosyl compounds: Ethers, thioethers and selenoethers. A survey of their synthesis and biological activity. Comptes Rendus Chim. 2011, 14, 274-285. [CrossRef] 
91. Stec, W.J.; Zon, G.; Egan, W. Automated solid-phase synthesis, separation, and stereochemistry of phosphorothioate analogs of oligodeoxyribonucleotides. J. Am. Chem. Soc. 1984, 106, 6077-6079. [CrossRef]

92. Mori, K.; Boiziau, C.; Cazenave, C.; Matsukura, M.; Subasinghe, C.; Cohen, J.S.; Broder, S.; Toulmé, J.J.; Stein, C.A. Phosphoroselenoate oligodeoxynucleotides: Synthesis, physico-chemical characterization, anti-sense inhibitory properties and anti-HIV activity. Nucleic Acids Res. 1989, 17, 8207-8219. [CrossRef]

93. Conlon, P.F.; Eguaogie, O.; Wilson, J.J.; Sweet, J.S.T.; Steinhoegl, J.; Englert, K.; Hancox, O.G.A.; Law, C.J.; Allman, S.A.; Tucker, J.H.R.; et al. Solid-phase synthesis and structural characterisation of phosphoroselenolatemodified DNA: A backbone analogue which does not impose conformational bias and facilitates SAD X-ray crystallography. Chem. Sci. 2019, 10, 10948-10957. [CrossRef]

94. Eguaogie, O.; Conlon, P.F.; Vyle, J.S. Synthesis of nucleoside phosphoroselenolates via the efficient MichaelisArbuzov reaction of selenocyanates. Tetrahedron Lett. 2016, 57, 5000-5002. [CrossRef]

95. Bartoszewicz, A.; Kalek, M.; Stawinski, J. The Case for the Intermediacy of Monomeric Metaphosphate Analogues during Oxidation of H-Phosphonothioate, H-Phosphonodithioate, and H-Phosphonoselenoate Monoesters: Mechanistic and Synthetic Studies. J. Org. Chem. 2008, 73, 5029-5038. [CrossRef]

96. Kowalska, J.; Lukaszewicz, M.; Zuberek, J.; Darzynkiewicz, E.; Jemielity, J. Phosphoroselenoate Dinucleotides for Modification of mRNA 5' End. ChemBioChem 2009, 10, 2469-2473. [CrossRef] [PubMed]

97. Jeong, L.S.; Tosh, D.K.; Kim, H.O.; Wang, T.; Hou, X.; Yun, H.S.; Kwon, Y.; Lee, S.K.; Choi, J.; Zhao, L.X. First Synthesis of 4'-Selenonucleosides Showing Unusual Southern Conformation. Org. Lett. 2008, 10, $209-212$. [CrossRef] [PubMed]

98. Tosh, D.K.; Choi, W.J.; Kim, H.O.; Lee, Y.; Pal, S.; Hou, X.; Choi, J.; Choi, S.; Jeong, L.S. Stereoselective Synthesis and Conformational Study of Novel 2', $3^{\prime}$-Didehydro-2' ${ }^{\prime} 3^{\prime}$-dideoxy-4'-selenonucleosides. J. Org. Chem. 2008, 73, 4259-4262. [CrossRef] [PubMed]

99. Jeong, L.S.; Choi, Y.N.; Tosh, D.K.; Choi, W.J.; Kim, H.O.; Choi, J. Design and synthesis of novel 2', $3^{\prime}$-dideoxy$4^{\prime}$-selenonucleosides as potential antiviral agents. Bioorg. Med. Chem. 2008, 16, 9891-9897. [CrossRef] [PubMed]

100. Jeong, L.S.; Tosh, D.K.; Choi, W.J.; Lee, S.K.; Kang, Y.-J.; Choi, S.; Lee, J.H.; Lee, H.; Lee, H.W.; Kim, H.O. Discovery of a New Template for Anticancer Agents: 2'-deoxy-2'-fluoro-4'-selenoarabinofuranosyl-cytosine (2'-F-4'-Seleno-ara-C). J. Med. Chem. 2009, 52, 5303-5306. [CrossRef]

101. Alexander, V.; Choi, W.J.; Chun, J.; Kim, H.O.; Jeon, J.H.; Tosh, D.K.; Lee, H.W.; Chandra, G.; Choi, J.; Jeong, L.S. A New DNA Building Block, 4'-Selenothymidine: Synthesis and Modification to 4'-Seleno-AZT as a Potential Anti-HIV Agent. Org. Lett. 2010, 12, 2242-2245. [CrossRef]

102. Yu, J.; Kim, J.-H.; Lee, H.W.; Alexander, V.; Ahn, H.-C.; Choi, W.J.; Choi, J.; Jeong, L.S. New RNA Purine Building Blocks, $4^{\prime}$-Selenopurine Nucleosides: First Synthesis and Unusual Mixture of Sugar Puckerings. Chem. A Eur. J. 2013, 19, 5528-5532. [CrossRef]

103. Inagaki, Y.; Minakawa, N.; Matsuda, A. Synthesis of 4 'selenoribo nucleosides. Nucleic Acids Symp. Ser. 2007, 51, 139-140. [CrossRef]

104. Jayakanthan, K.; Johnston, B.D.; Pinto, B.M. Stereoselective synthesis of $4^{\prime}$-selenonucleosides using the Pummerer glycosylation reaction. Carbohydr. Res. 2008, 343, 1790-1800. [CrossRef]

105. Abdo, M.; Knapp, S. Biomimetic Seleninates and Selenonates. J. Am. Chem. Soc. 2008, 130, 9234-9235. [CrossRef]

106. Jordheim, L.P.; Durantel, D.; Zoulim, F.; Dumontet, C. Advances in the development of nucleoside and nucleotide analogues for cancer and viral diseases. Nat. Rev. Drug Discov. 2013, 12, 447-464. [CrossRef] [PubMed]

107. Lee, H.; Jarhad, D.B.; Yu, J.; Lee, C.; Jeong, L.S. Asymmetric Synthesis of 2'-C-Methyl-4'-selenonucleosides as Anti-Hepatitis C Virus Agents. J. Org. Chem. 2019, 84, 14414-14426. [CrossRef] [PubMed]

108. Bur, S.K.; Padwa, A. The Pummerer Reaction: Methodology and Strategy for the Synthesis of Heterocyclic Compounds. Chem. Rev. 2004, 104, 2401-2432. [CrossRef] [PubMed]

109. Byun, W.S.; Jin, M.; Yu, J.; Kim, W.K.; Song, J.; Chung, H.-J.; Jeong, L.S.; Lee, S.K. A novel selenonucleoside suppresses tumor growth by targeting Skp2 degradation in paclitaxel-resistant prostate cancer. Biochem. Pharmacol. 2018, 158, 84-94. [CrossRef]

110. Sahu, P.K.; Kim, G.; Yu, J.; Ahn, J.Y.; Song, J.; Choi, Y.; Jin, X.; Kim, J.-H.; Lee, S.K.; Park, S.; et al. Stereoselective Synthesis of 4'-Selenonucleosides via Seleno-Michael Reaction as Potent Antiviral Agents. Org. Lett. 2014, 16, 5796-5799. [CrossRef] 
111. Sun, H.; Sheng, J.; Hassan, A.E.A.; Jiang, S.; Gan, J.; Huang, Z. Novel RNA base pair with higher specificity using single selenium atom. Nucleic Acids Res. 2012, 40, 5171-5179. [CrossRef]

112. Braga, A.L.; Severo Filho, W.A.; Schwab, R.S.; Rodrigues, O.E.D.; Dornelles, L.; Braga, H.C.; Lüdtke, D.S. Synthesis of selenium- and tellurium-containing nucleosides derived from uridine. Tetrahedron Lett. 2009, 50, 3005-3007. [CrossRef]

113. Abdo, M.; Zhang, Y.; Schramm, V.L.; Knapp, S. Electrophilic Aromatic Selenylation: New OPRT Inhibitors. Org. Lett. 2010, 12, 2982-2985. [CrossRef]

114. Salon, J.; Jiang, J.; Sheng, J.; Gerlits, O.O.; Huang, Z. Derivatization of DNAs with selenium at 6-position of guanine for function and crystal structure studies. Nucleic Acids Res. 2008, 36, 7009-7018. [CrossRef]

115. Kaur, M.; Huang, Z. Synthesis and optical behaviors of 6-seleno-deoxyguanosine. Sci. China Chem. 2014, 57, 314-321. [CrossRef]

116. Zhou, X.; Yan, W.; Zhang, C.; Yang, Z.; Neubauer, P.; Mikhailopulo, I.A.; Huang, Z. Biocatalytic synthesis of seleno-, thio- and chloro-nucleobase modified nucleosides by thermostable nucleoside phosphorylases. Catal. Commun. 2019, 121, 32-37. [CrossRef]

(C) 2020 by the authors. Licensee MDPI, Basel, Switzerland. This article is an open access article distributed under the terms and conditions of the Creative Commons Attribution (CC BY) license (http://creativecommons.org/licenses/by/4.0/). 